\title{
Ombres et lumières du tombeau peint découvert par A. B. Ašik
}

\section{Pascal Burgunder}

\section{(2) OpenEdition \\ 1 Journals}

Édition électronique

URL : https://journals.openedition.org/edl/1720

DOl : $10.4000 /$ edl. 1720

ISSN : 2296-5084

\section{Éditeur}

Université de Lausanne

\section{Édition imprimée}

Date de publication : 15 mai 2019

Pagination : 181-242

ISBN : 978-2-940331-70-3

ISSN : 0014-2026

\section{Référence électronique}

Pascal Burgunder, "Ombres et lumières du tombeau peint découvert par A. B. Ašik », Études de lettres [En ligne], 309 | 2019, mis en ligne le 15 mai 2021, consulté le 17 mai 2021. URL : http://

journals.openedition.org/edl/1720; DOI : https://doi.org/10.4000/edl.1720 


\section{OMBRES ET LUMIÈRES DU TOMBEAU PEINT DÉCOUVERT PAR A. B. AŠIK*}

Le tombeau peint mis au jour à Kertch par Anton Ašik passe aujourd'hui pour perdu. La découverte avait pourtant fait sensation, en 1842, lorsque la richesse de ses compositions peintes, demeurées en excellent état de conservation, se révéla à l'archéologue et à son dessinateur. Ils procédèrent en quelques jours à la copie des peintures. Ces relevés seront à la base d'une publication consacrée au monument funéraire dont certains exemplaires destinés à de hauts personnages seront illustrés de dessins coloriés à la main. Une patiente enquête nous a mené à retrouver deux exemplaires coloriés, déposés dans des musées russes de renom. Ces trouvailles, portées pour la première fois à la connaissance du public, offrent l'occasion de se pencher à nouveau sur cet extraordinaire hypogée.

À la mémoire de Nikolaj Fjodorovič Fedoseev (1961-2018)

\section{Introduction}

Le luxe et la variété des compositions peintes recouvrant parois et plafonds d'un tombeau à deux chambres auraient dû assurer à ce fastueux monument funéraire creusé dans le flanc nord-ouest du mont Mithridate, à Kertch (voir les cartes A et B, p. 21 et 22), autant une gloire méritée que les conditions de sa préservation. Hélas, en l'absence de toute décision administrative énergique, les peintures s'abîmèrent

* La présente contribution a été réalisée dans le cadre du projet «Ancient Painting from the Cimmerian Bosporus. From drawing to photography» soutenu financièrement par le Fonds National Suisse pour la recherche scientifique (FNS). 
rapidement et l'accès à l'hypogée fut bientôt perdu: le tombeau découvert en 1842 par Anton Baltazarovič Ašik, alors directeur du muséum de Kertch, alla ainsi rejoindre la longue liste des monuments antiques disparus et partager le destin d'autres tombeaux peints ouverts durant la première moitié du XIX ${ }^{\mathrm{e}}$ siècle ${ }^{1}$.

Le mérite revient à A. B. Ašik d'avoir immédiatement saisi l'importance de sa découverte et d'avoir entrepris d'en reproduire aussitôt les compositions peintes. C'est ainsi que seuls subsistèrent du tombeau des dessins réalisés en quelques jours à la lumière d'une chandelle! Anton Ašik avait alors pu profiter du concours d'un dessinateur rattaché au muséum, Andrej Stefanskij, et les relevés qu'ils produisirent ensemble servirent à illustrer une publication du monument funéraire en langue russe qui paraîtrait à Odessa en 1845 sous le titre Kerčenskie drevnosti o pantikapejskoj katakombe, ukrašennoj freskami [Les Antiquités de Kertch. Sur une catacombe peinte de Panticapée].

Lorsqu'il entreprit, une soixantaine d'années plus tard, de rédiger son ouvrage consacré aux monuments peints de l'Antiquité gréco-romaine mis au jour en Russie méridionale, Mikhail Rostovcev s'astreignit tout d'abord à un important travail de recherche en archives ${ }^{2}$. Pour précieux qu'en fût le témoignage, l'opuscule d'Ašik avait en effet été diversement apprécié: l'interprétation des compositions peintes était jugée fantasque et la qualité des dessins soulevait des interrogations quant à sa fidélité à l'original ${ }^{3}$. Rostovcev chercha donc à obtenir des informations supplémentaires que ne contiendrait pas la publication d'Ašik. En vain,

I. On peut notamment citer le tombeau des Pygmées ouvert en 1832 par Damian Vasil'evič Karejša (voir M. I. Rostovcev, Antičnaja dekorativnaja živopis' na juge Rossii, p. 137-149) ou encore le tombeau de 1852 mis au jour par Kirill Rodionovič Begičev (voir ibid., p. 153-160).

2. Le tombeau peint découvert par Anton Ašik occupe une place de choix au sein de l'ouvrage du célèbre savant: il fait l'objet d'une présentation et d'un descriptif critique long d'une trentaine de pages et témoignant de la valeur exceptionnelle de l'hypogée, voir M. I. Rostovcev, Antičnaja dekorativnaja živopis' na juge Rossii, p. 346-375.

3. La recension de B. von Köhne, parue dans trois revues différentes, reflète de manière circonstanciée l'opinion de la société savante de Saint-Pétersbourg, voir B. V. Kjone, «Recenzija sočinenija G. Ašika: Kerčenskija drevnosti. O Pantikapejskoj katakombe, ukrašennoj freskami, Odessa, 1845»; B. de Köhne, "A. Ašik, Antiquités de Kertsch : catacombe de Panticapée avec des fresques peintes»; B. V. Kjone, "Otčjot o sočinenii G. Ašika, pod zaglaviem: Kerčenskija drevnosti. O Pantikapejskoj katakombe, ukrašennoj freskami. Odessa, 1845 ». 
puisque ses investigations ne lui permirent ni de mettre la main sur les dessins originaux ni même d'arrêter avec certitude la date de la découverte du tombeau. Par surcroît, il ne parvint à se procurer des exemplaires aux planches coloriées que tardivement, ce qui entraîna peut-être leur reproduction en noir-blanc dans son atlas de planches.

Ces reproductions-là furent ensuite colportées dans la littérature scientifique au gré des problématiques abordées: la séquence relevant des mystères éleusiniens (Pl. V, p. 234) apparaît régulièrement ${ }^{4}$, tandis que la problématique du luminaire (Pl. III, p. 232 et Pl. VIII, p. 237) est plus rarement traitée 5 . La reproduction de la bataille équestre décorant la banquette funéraire du tombeau (Pl. IV, p. 233) constitue sans doute la composition peinte la plus fréquemment sollicitée pour sa valeur historique dans le champ des militaria ${ }^{6}$.

Plus de cent ans après la parution de l'ouvrage de M. I. Rostovcev, resté à ce jour une référence 7 , il nous paraissait opportun de revenir à ce monument funéraire emblématique - peut-être le plus connu de Kertch avec le célèbre tombeau de Déméter - et à sa publication première. L'actualisation de nos connaissances archéologiques, une accessibilité plus grande aux archives et, surtout, la découverte inespérée d'exemplaires coloriés des Kerčenskie drevnosti [Les Antiquités de Kertch] dans des musées de SaintPétersbourg et de Iaroslavl allaient permettre de se pencher à nouveau sur ce dossier avec des armes nouvelles. Convaincu avec Irina Vladimirovna Tunkina que la documentation établie par Ašik et ses contemporains est suffisante pour restituer des monuments archéologiques perdus et le

4. Voir en dernier lieu A.-M. Guimier-Sorbets, A. Pelle, M. Seif el-Din, Renaître avec Osiris et Perséphone, p. 126, fig. 172.

5. Voir P. Burgunder, "Des lumières de la tombe d'Ašik».

6. A. K. Nefjodkin, Pod znamenem drakona, p. 38 sq. (cataphractaires sarmates et leur équipement); V. A. Gorončarovskij, Meždu imperiej $i$ Varvarami, p. 76 (arc) et p. 108 (scène de bataille); également dans Ju. A. Vinogradov, V. A. Gorončarovskij, Voennaja istorija i voennoe delo Bospora Kimmerijskogo (VI v. do n.è. - seredina III v. n.è.), fig. 107, p. 212 (même contexte); M. Mielczarek, Cataphracti and clibanarii, fig. 23, p. 141 et The army of the Bosporan kingdom, pl. XXV; I. Lebedynsky, Les Sarmates, p. 165 (lanciers équipés dans le style sarmato-alain).

7. Louvrage centenaire de Rostovcev a fait l'objet, faut-il le rappeler, d'une traduction française parue à l'initiative d'Alix Barbet: M. I. Rostovtseff, La peinture décorative antique en Russie méridionale (Saint-Pétersbourg, 1913-1914). 
contexte de leur mise au jour ${ }^{8}$, nous proposons dans cette contribution de mieux cerner le moment probable de la découverte du tombeau et de mieux le situer aussi, à l'aide d'une carte de Kertch et de ses environs dressée en 1835 par un topographe. L'ouvrage de 1845 consacré au caveau funéraire et à ses peintures regorge en outre d'informations autant personnelles que savantes susceptibles de nourrir l'ébauche d'un contexte à sa production - nous initions ici une enquête qui verra sans doute Anton Ašik réhabilité dans son œuvre et dans ses qualités d'archéologue.

\section{La découverte du tombeau}

Ni l'emplacement précis du tombeau ni la date de son ouverture ne sont dûment enregistrés: évoquant tantôt l'année 1842 dans l'introduction de son opuscule (p. III), tantôt l'année 1841 dans le premier chapitre du même ouvrage (chapitre I, p. 3), Anton Ašik n'est pas plus précis dans sa correspondance aux diverses instances de tutelle. Seul le recoupement de la documentation d'archives, dispersée entre plusieurs institutions, permet de proposer une date vraisemblable pour la découverte du tombeau peint.

\subsection{L'apport des archives}

L'Institut d'histoire de la culture matérielle, dépositaire des archives de la Commission archéologique impériale, conserve un document intitulé "Spisok s kratkogo izvestija ob otkrytii drevnostej Direktorom Kerčenskogo muzeuma Ašikom» " Copie du bref bulletin des découvertes d'antiquités réalisées par le directeur du muséum de Kertch Ašik»]. Il couvre une période allant du 29 août [1841] au $1^{\text {er }}$ avril 1842 et fait un bref rapport de la découverte du tombeau ${ }^{9}$. Sans doute s'agit-il là d'un extrait du rapport que cite Rostovcev, "Otčjot o razyskanijakh drevnostej, proizvedjonnykh v Kerči s 1821 po 1842 g.» ["Rapport sur

8. Voir I. V. Tunkina, Russkaja nauka o klassičeskikh drevnostjakh juga Rossii (XVIII - seredina XIXvv.), p. 271.

9. RA IIMK, F. 63, d. 5, 11. 129 (verso) et 130; l'année 1841 est reportée au crayon de papier après la mention du 29 août. Ce document est cité par I. V. Tunkina, Russkaja nauka o klassičeskikh drevnostjakh juga Rossii (XVIII - seredina XIX vv.), p. 294. 
les recherches d'antiquités faites à Kertch de 1821 à 1842 », couvrant une période plus longue, mais offrant une description sensiblement identique des circonstances ayant présidé à l'ouverture du tombeau ${ }^{10}$.

Ce document déposé à l'Institut aura été traduit en français puisque les Archives scientifiques du Musée d'État de l'Ermitage en produisent l'exact pendant, sous un titre identique:

Sur des fouilles, exécutés par M. Aschik du 29 Août 1841 jusqu'au 1 Avril 1842.

[...] Après cette trouvaille M. Aschik a transporté ses travaux du côté de Mont Mithridate à la distance de $1^{1 / 2}$ verstes de Kertch, et dans cet endroit il a ouvert 14 catacombes, qui étaient déjà tous dévalisés, mais dans la $15^{\text {ème }}$ il a trouvé deux chambres, dont les murailles étaient couvertes de fresques, très intéressants, dans le genre de ceux, qui furent découvertes à Tarquinia ${ }^{11}$.

La correspondance échangée avec Saint-Pétersbourg permet de situer le moment de la découverte du tombeau durant les deux premiers mois de l'année 1842, puisqu'il en est fait brièvement mention dans une lettre datée du 3 mars 1842 et adressée à Florian Gille ${ }^{12}$. D'autres documents, aujourd'hui déposés à Kiev, viennent indubitablement confirmer la fin du mois de février, voire le tout début du mois de mars 1842, comme moment de la mise au jour de l'hypogée peint: quelques pièces de la correspondance "de service» du comte Mikhail Voroncov, généralgouverneur de Nouvelle Russie et Bessarabie, restituent les aléas administratifs et les vains efforts d'Ašik pour préserver le tombeau peint de la destruction ${ }^{13}$. En réponse à un premier courrier l'informant de

Io. Voir M. I. Rostovcev, Antičnaja dekorativnaja živopis’ na juge Rossii, p. 346.

II. Extrait du feuillet 14 (recto et verso), F. 1, op. 1, d. 21 (1837) intitulé «O raskopkakh Ašik v Kerči za 1837-1842» ["Fouilles d’Ašik à Kertch de 1837 à 1842»]. Sans doute cette traduction a-t-elle été produite par F. Gille pour les besoins de l'ouvrage qu'il avait d'abord en tête de publier.

I2. AGÈ F. 1, op. 1, d. 21 (1841) - citée déjà par Rostovcev dans Antičnaja dekorativnaja živopis' na juge Rossii, p. 346. Deux lettres conservées, celle datée du $1^{\mathrm{er}}$ janvier 1842 ( $\mathrm{N}^{\circ}$ 9) et celle datée du 3 mars 1842 ( $\mathrm{N}^{\circ}$ 14), témoignent tant de la fréquence des relations épistolaires entre les deux hommes que de la fourchette chronologique durant laquelle intervient certainement la découverte.

I3. Correspondance conservée à l'Institut des manuscrits de la Bibliothèque Nationale d'Ukraine, F. V, feuillet 1220 sq. (1842). Mes remerciements vont à Julija Dud'ka et à Aleksandr Kuz'miščev pour leur aide à se procurer copie du dossier. 
la découverte du tombeau, Voroncov se félicite de pareille nouvelle et prie le directeur du muséum de Kertch de rédiger la description détaillée de l'hypogée et d'en réaliser des dessins "aux couleurs identiques à l'original» à l'attention de la Société d'histoire et d'antiquités d'Odessa. Le général-gouverneur invite, par pli séparé et rédigé à l'attention du gouverneur de la ville de Kertch, à prendre les dispositions nécessaires à la sauvegarde du monument. Mais aucun moyen n'ayant été rapidement consenti à la garde du monument, Ašik se voit contraint de mettre le gouverneur de Kertch, le prince Kherkheulidzev, devant ses responsabilités, ce qu'il fait par écrit dans une lettre datée du 18 mars:

J'ai informé verbalement Votre Excellence de la découverte de la catacombe à fresques. Sachant que rien ici ne peut échapper aux fouilles sauvages des chercheurs d'or, j'y ai placé à mes frais un garde pendant deux semaines, durée qu'ont nécessitée les relevés des fresques. Depuis lors, la catacombe a déjà été visitée par des vandales et les peintures sont déjà très endommagées en de nombreux endroits. Je n’ai aucune possibilité de les protéger; il faudrait y placer un garde en permanence ou y construire une porte bardée de fer. Si nous avions à notre service des gardes à cheval, ils réussiraient à prévenir la destruction de nombreux monuments antiques, mais le directeur du muséum ne peut rien faire sans aides et sans moyens ${ }^{14}$.

\subsection{La perte du tombeau}

Dans les dernières lignes du chapitre I de son opuscule, Ašik prédit la disparition prochaine des compositions peintes, cherchant peut-être à se disculper de la perte totale du monument à l'heure où il publiait:

Le lendemain de l'ouverture, l'humidité imprégnait les parois, les couleurs commençaient à blêmir, le stuc à se détacher des murs et à tomber au plus léger contact ${ }^{15}$.

\footnotetext{
I4. Le brouillon de la lettre était conservé à Kertch où il périt, de même que la plus grande partie des archives du musée, durant la Seconde Guerre mondiale. Copie en avait toutefois été reproduite par V. V. Škorpil à l'attention de M. I. Rostovcev (qui la restitue dans Antičnaja dekorativnaja živopis'na juge Rossii, p. 347). La traduction française est celle empruntée à l'édition Barbet.

I5. A. B. Ašik, Kerčenskie drevnosti o pantikapejskoj katakombe, ukrašennoj freskami, p. 4.
} 
Le sort ultérieur des peintures et du tombeau lui-même ne fait guère de doute pour M. I. Rostovcev qui documente dans le détail l'histoire des tombeaux peints de Kertch. Le mandat qu'il confie à V. V. Škorpil de retrouver la trace du monument funéraire tend à vérifier son pressentiment: sans doute le tombeau a-t-il été entièrement détruit, peut-être encore du vivant d'Ašik ${ }^{16}$. Un nouveau rapport adressé au gouverneur de Kertch à mi-décembre 1845 ne paraît pas hésiter sur le sort réservé au tombeau de 1842 :

C. Catacombes creusées dans le rocher. Les parois de l'une d'elles portaient des fresques, au sujet desquelles je publierai un ouvrage particulier; outre ces fresques, on découvrit également un tombeau sur les murs duquel figurait un épisode de la célèbre guerre des Pygmées contre les grues, mais tout cela est totalement anéanti; il serait actuellement difficile de trouver ne serait-ce que des traces de ces monuments ${ }^{17}$.

Les investigations entreprises par Škorpil dans un secteur de la ville de Kertch désormais entièrement bâti avaient été précédées, à plusieurs reprises, de démarches identiques entamées d'abord par Aleksandr Ljucenko, puis par Nikodim Kondakov, et restées toutes infructueuses. Successeur d'Anton Ašik à la tête du muséum de Kertch, Aleksandr Ljucenko aura tenté, à en croire l'information que nous en laisse Vladimir Stasov ${ }^{18}$, de retrouver le tombeau peint durant ses années de directorat (il est formellement en fonction de 1853 à 1878, mais délaisse le terrain pour raison de santé dès 1869). Les "Compte rendus pour les années 1878 et 1879 » se font à leur tour l'écho d'une zone de recherche s'étendant, parmi les tumuli, "près des fours à chaux du sieur Rostovsky

I6. Voir M. I. Rostovcev, Antičnaja dekorativnaja živopis' na juge Rossii, p. 348. Le tombeau est demeuré introuvable malgré la mise en œuvre de recherches systématiques en 1906 (dans les environs du tombeau de 1873, sur la rue Nagornaja et sur une zone s'étendant jusqu'au cimetière tatare, là où passe la route menant à Théodosie, aux pieds de six collines) et en 1907. Voir à ce propos Ju. A. Vinogradov, M. V. Medvedeva, «Iz istorii sozdanija "Antičnoj dekorativnoj živopisi na juge Rossii” M. I. Rostovceva", en particulier p. 15 sq.

I7. Lettre datée du 16.12.1845, voir M. I. Rostovcev, Antičnaja dekorativnaja živopis' na juge Rossii, p. 347. J'ignore si ce document s'est conservé. Le tombeau des Pygmées (1832) est présenté par Rostovcev dans le même ouvrage, p. 137-149.

I8. Voir le "CR de la Commission impériale archéologique pour l'année 1872 ", Saint-Pétersbourg, 1875, p. 255, n. 3. 
et du moulin à vent", et placée sous la houlette de Kondakov ${ }^{19}$. Le savant ne s'est toutefois pas arrêté à cette seule tentative et reprend son enquête en 1882, éclairé cette fois des «indications d'un vieil habitant de la contrée " ${ }^{20}$. Mais ses prospections, sans doute réalisées sur le versant nord de "l'Allée des kourganes", à l'endroit des premiers remblais funéraires, n'aboutirent pas. L'expansion de la ville est alors déjà incriminée et le tombeau peint supposé recouvert et inaccessible.

\subsection{La situation du tombeau}

Les critiques adressées à Anton Ašik se sont régulièrement indignées du fait que le directeur du muséum de Kertch ait totalement négligé l'élaboration d'une carte archéologique répertoriant les multiples fouilles et découvertes accumulées pendant ses nombreuses années d'investigations. Le reproche est fondé et la négligence d'Ašik ne s'explique guère, à considérer la couverture topographique pléthorique dont la ville et ses environs ont joui durant tout le XIXe siècle - l'importance stratégique et économique du port de Kertch justifiant assurément la richesse du fonds de cartes et de relevés couvrant toute la région.

Des ouvrages publiés par Ašik un seul, le premier tome de Vosporskoe Carstvo, paru à Odessa en 1848, est équipé de quelques cartes: la planche IV, un "plan schématique de l'acropole de Panticapée et de la ville actuelle de Kertch", est l'unique repère topographique à pouvoir satisfaire la curiosité du lecteur (fig. 1). S'il nous renseigne sur le tracé emprunté par l'enceinte de la cité antique, le plan schématique ne dit rien de l'emplacement des monuments funéraires mis au jour par Ašik ${ }^{21}$. Aucune mention du tombeau peint ni aucun indice exploitable pour en fixer l'emplacement, si ce n'est la lettre « $E$ » inscrite à l'endroit d'où

19. "CR de la Commission impériale archéologique pour les années 1878 et 1879", Saint-Pétersbourg, 1881, p. XVI.

20. "CR de la Commission impériale archéologique pour les années 1882 à 1888 ", Saint-Pétersbourg, 1893, p. IX sq.

2I. La critique de E. P. Ševeljov (in ZOOID II, 1848, p. 725-738) à l'adresse du "plan de Kertch» reproduit en planche I du premier volume de Vosporskoe Carstvo s ego paleograficeskimi i nadgrobnymi pamjatnikami, raspisnymi vazami, planami, kartami $i$ vidami concerne en réalité non un plan topographique, mais une gravure jugée fantasque et manifestement reprise par Ašik du tome II des Nouvelles annales des voyages, de la géographie et de l'histoire (Paris, 1819). 
Fig. 1 - Carte de Kertch et de l'acropole de Panticapée, tirée de A. B. Ašik, Vosporskoe Carstvo s ego paleografičeskimi i nadgrobnymi pamjatnikami, raspisnymi vazami, planami, kartami i vidami [Le Royaume du Bosphore avec ses monuments paléographiques et funéraires, ses vases peints, des plans, des cartes et des vues], Odessa, Tipografija T. Nejmana i komp., 1848, (partie 1), Pl. IV. Le point E correspond au «šlagbaum». Infographie de D. Glauser ( ) UNIL/IASA.

s'étire un chemin quittant la ville et en fixant la limite avant de parcourir ses faubourgs - témoignage de l'extension incessante de Kertch au $\mathrm{XIX}^{\mathrm{e}}$ siècle.

Nous avons donc cherché à combler ce manquement en nous équipant d'un plan topographique de Kertch établi en 1835 par un certain Litvinenko ${ }^{22}$. Plusieurs relevés du même topographe sont mentionnés

22. Nos remerciements vont à Sergej Smekalov (Saint-Pétersbourg) et à Arsenij Mikhajlov (Kertch) pour nous avoir guidé dans nos recherches. Il s'agit d'un plan appartenant à un portefeuille de douze cartes intitulé «Plan topographique de la ville de Kertch-Iénikalé avec mention des hameaux et des terres de ses environs (...). Dressé sur instrument en 1835 (...) par le topographe de deuxième classe Litvinenko». 
dans la littérature scientifique, mais c'est l'exemplaire conservé au département de cartographie de la Bibliothèque Nationale de Russie, à Moscou, qui servira de support à notre enquête ${ }^{23}$. L'exploitation de ce document est d'un intérêt triple: il restitue la topographie de Kertch et de ses alentours immédiats à une date légèrement antérieure au moment de la découverte du tombeau; il reproduit le relief d'éminences rocheuses ainsi que le tissu urbain avec soin et précision; enfin, il rend réseau routier et tertres funéraires aisément lisibles, ce qui constitue un auxiliaire précieux de notre démarche.

Combiné aux renseignements que nous livre le rapport d'Ašik, le plan topographique de Litvinenko est susceptible de nous apporter de nouvelles informations utiles à situer le tombeau découvert par Anton Ašik durant les premiers mois de l'année 1842 (fig. 2). L’hypogée peint est sommairement localisé "sur le flanc nord du mont Mithridate", "à la distance de $1^{1 / 2}$ verstes de Kertch» et intègre "un endroit où se trouvent un grand nombre de catacombes panticapéennes disposées en rangs » 24 - ces éléments devant permettre de situer, dans un premier effort de repérage, son emplacement potentiel.

Sur la carte de Litvinenko, le flanc septentrional du mont Mithridate - compris dans une acception large, comme une chaîne rocheuse s'étendant du Premier fauteuil de Mithridate en direction du kourgane d'Or ("Zolotoj kurgan», en russe) - montre une grande densité de tertres funéraires (signifiés parfois en jaune, lorsqu'ils ont été explorés) augmentant à hauteur de l'éminence rocheuse appelée «Pain de sucre». On note l'existence d'un chemin traversant cette nécropole d'est en ouest et que M. I. Rostovcev désigne du terme d' "Allée des kourganes» ${ }^{25}$. La partie de la nécropole située au bas d'une hauteur rocheuse voisine, appelée

23. Nos remerciements pour leur collaboration vont à L. N. Zinčuk, responsable du département de cartographie, et à A. S. Mitrofanova, responsable des ressources en ligne de la Bibliothèque Nationale de Russie à Moscou.

24. Voir le feuillet 14 (recto et verso), F. 1, op. 1, d. 21 (1837) aux Archives de l'Ermitage et, à l'Institut d'histoire de la culture matérielle, F. 63, d. 5, feuillet 129 (verso).

25. L'Allée des kourganes est mentionnée sur la Pl. I d'Antičnaja dekorativnaja živopis' na juge Rossii. Désignation aujourd'hui oubliée, l' "Allée des kourganes» de Kertch semble être inspirée de la topographie funéraire de Phanagorie; c'est ainsi appairée qu'elle apparaît dans l'ouvrage d'A. A. Matveev, Kvoprosu ob arkheologičeskikh issledovanijakh v Južnoj Rossii, p. 39. 


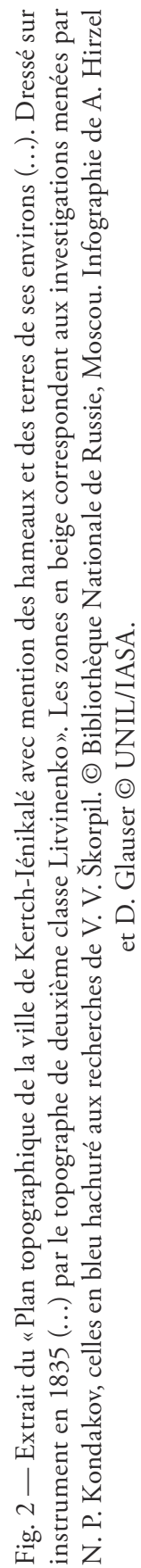


"Rocher long", compte déjà plusieurs rangées de tertres, réparties principalement au pied et sur le flanc nord du Rocher; elle se densifie encore dans son extension occidentale, en direction du kourgane d'Or.

La troisième indication pouvant servir à localiser le tombeau ouvert par Ašik, apparemment la plus précise, n'est pourtant pas la plus fiable. Quel crédit accorder à la distance "d'une verste et demie" mesurée à partir de Kertch? Et de quel endroit lancer la chevillère? La carte dressée par Litvinenko semble confirmer ce que suggère, avec sa lettre " $\mathrm{E}$ ", le plan schématique d'Ašik: le lieu où l'on entre et sort de la ville de Kertch est clairement signifié par une barrière, que le russe nomme (de l'allemand) «šlagbaum» ${ }^{26}$. De la placette située par-devers ce point part la route de Théodosie, reliant Kertch au reste de la Crimée ${ }^{27}$. Il est donc fort à parier qu'Ašik estime la distance séparant le tombeau de la ville précisément à partir de cet endroit. Mais peut-on seulement faire crédit à l'inventeur de la tombe d'une grande précision dans l'appréciation de la distance? Il paraît en effet plus probable que la distance rapportée l'ait été «à la louche» ("une verste sur le chemin, une demi-verste dans les prés») - une hypothèse que pourrait confirmer le plan des lieux fournis par M. I. Rostovcev.

Sur le plan du versant septentrional du mont Mithridate qui ouvre l'atlas des planches de sa "Peinture décorative antique en Russie méridionale», M. I. Rostovcev situe plusieurs tombeaux peints susceptibles, stylistiquement, d'être contemporains de celui ouvert par Ašik. Nous en avons reproduit l'emplacement approximatif sur la carte de Litvinenko pour en signifier la proximité géographique et celle, il faut bien en présumer ainsi, de la tombe perdue de 1842 . Toutes y ont été mises au jour entre la fin des années 1860 et 1890, année qui vit le professeur Julian Kulakovskij ouvrir le tombeau peint de Sôrakos. Ce dernier, rapporte Rostovcev, est implanté au pied du "Rocher long", au-dessus du quartier tatar, à un endroit "aujourd'hui encore inoccupé» 28 . Donnant sur la même "Allée des kourganes", mais un peu plus à l'est, le tombeau dit de Stasov, découvert en 1872, est réputé se trouver «à proximité du

26. Portes de villes dans la Russie du XVIII et du XIX ${ }^{\mathrm{e}}$ siècle, les passages gardés par le «šlagbaum» sont surveillés par une sentinelle.

27. Cette voie faisait office également de "route de poste» comme on l'apprend de plusieurs cartes postérieures.

28. Voir M. I. Rostovcev, Antičnaja dekorativnaja živopis' na juge Rossii, p. 244 et le mémoire de J. Kulakovskij, Dve Kerčenskie katakomby s freskami, p. 16-33. 
tombeau de Sorakos ${ }^{29}$. L'emplacement du tombeau de 1873 est également connu et fixé à proximité de celui décrit par Stasov, sur « un terrain vague en 1891 encore» et dont Rostovcev craint qu'il ne devienne bientôt propriété privée ${ }^{30}$. Si sa localisation n'en est plus certaine au début $\mathrm{du} \mathrm{XX}^{\mathrm{e}}$ siècle, on sait par les informations que nous livrent les "Compte rendus pour l'année 1875 » que le tombeau de 1875 était implanté parmi les tertres funéraires qui se dressaient au pied du «Pain de sucre», non loin des fours à chaux ${ }^{31}$.

Nous sommes donc enclin à localiser l'emplacement du tombeau de 1842 non loin de l'«Allée des kourganes", dans la proximité des tombeaux susmentionnés de Sôrakos, de Stasov et de 1873 ou, plus largement, dans un périmètre s'étendant de la zone explorée par Kondakov en 1882 à celle, plus à l'ouest, explorée en 1906 par V. V. Škorpil.

\subsection{Larchitecture du tombeau}

Dans son opuscule, Ašik ne se prive pas de mettre en scène ses activités de directeur du muséum de Kertch: il se targue d'une longue expérience du terrain qui lui vaut non seulement de pouvoir établir une véritable morphologie des kourganes qu'il explore, mais encore de savoir y repérer sans faute, par une méthode originale qu'il a éprouvée maintes fois, l'endroit signalant l'entrée de la tombe. Dès 1834, le premier, écrit Ašik à l'initiale de ses Kerčenskie drevnosti [Antiquités de Kertch], alors que d'autres archéologues y auraient été totalement insensibles, il perçoit une tache d'humidité immanquablement située au pied de chacun des kourganes, sur leur flanc nord-est, et trahissant la présence, à environ un mètre de la surface, d'un puits d'accès s'enfonçant dans la roche (du calcaire coquillier, précise-t-il) pour déboucher sur l'entrée taillée en berceau de l'hypogée.

Ašik reprend ses investigations en 1841, sans doute à l'automne, dans cette partie de la nécropole tumulaire de Panticapée s'étirant à partir $\mathrm{du}$ «Pain de sucre» en direction de l'ouest, et qui compte des kourganes

29. Voir M. I. Rostovcev, Antičnaja dekorativnaja živopis' na juge Rossii, p. 293 "près de la route menant au kourgane Zolotoj».

30. Ce qui le conduirait à la ruine, assure M. I. Rostovcev dans la section d'Antičnaja dekorativnaja živopis’ na juge Rossii, p. 227, consacrée au monument funéraire.

3I. Voir M. I. Rostovcev, Antičnaja dekorativnaja živopis’ na juge Rossii, p. 283. 
se dressant sur plusieurs rangs. Ašik met au jour quatorze hypogées, tous visités avant lui. Le quinzième se révèle du plus haut intérêt par son ampleur (il est à deux chambres) et par la présence de riches compositions peintes ornant parois et plafonds.

Autant le faciès géologique que la primauté des découvertes sont remis en cause par Julian Kulakovskij qui, dans son mémoire paru en 1896 Dve Kerčenskie katakomby s freskami [Deux catacombes de Kertch avec fresques], s'empresse de rectifier les propos d'Ašik. Les "catacombes» de Kertch ne sont pas taillées dans la roche, mais dans une couche de glaise argileuse reposant stratigraphiquement sous le calcaire poreux et au travers duquel sont creusés les puits d'accès; quant aux premières découvertes de ce type de monuments funéraires, poursuit Kulakovskij, elles reviennent en réalité à Paul Du Brux et à Frédéric Dubois de Montperreux ${ }^{32}$.

La terminologie employée par Ašik est également discutée par le professeur Kulakovskij, en particulier dans l'acception que prendrait à Kertch le terme de "catacombe». La spécificité de son emploi, qualifiant presque exclusivement les cimetières souterrains des chrétiens de Rome, interdit a priori d'en faire usage à Kertch et, n'était la force de la tradition et l'autorité conférée par son entrée dans des publications de référence, exige du moins quelques explications. Ainsi l'hypogée ouvert en 1842 n'est pas une cavité naturelle, comme semblerait le suggérer le terme promu par Anton Ašik de "grobničnye peščery" ["grottes funéraires"], ni une "catacombe" taillée dans la roche, mais bien un caveau funéraire aménagé dans une strate meuble du sous-sol et maçonné de sorte à pouvoir recevoir enduits et décors peints, voire décors stuqués, et à être équipé d'une niche principale, destinée à accueillir le défunt, et de niches secondaires.

\section{a) Le tertre funéraire}

La planche II de l'opuscule d'Ašik (Pl. II, p. 231) indique l'existence d'une élévation au-dessus du tombeau, interprétée comme étant un kourgane, c'est-à-dire un amoncellement d'origine anthropique constitué principalement de terre et signalant une sépulture. Ašik relève avec une grande précision la distance séparant le plafond de la tombe du sommet du kourgane, 3,86 m, ce qui semble relativiser la majesté du monument

32. Voir J. Kulakovskij, Dve Kerčenskie katakomby s freskami, p. 1-3. 
funéraire ${ }^{33}$. Pareille impression pourrait être trompeuse: il est en effet fort probable que le kourgane ait lui-même été érigé sur une éminence rocheuse ou sur son flanc, le rehaussant ainsi à la vue du passant ${ }^{34}$.

L'édification d'un kourgane sur une hauteur naturelle n'a rien d'étonnant et n'offre a priori pas de repère chronologique: la crête rocheuse de Juz-Oba, s'étirant à une quinzaine de kilomètres de Kertch, est ellemême hérissée de kourganes dont les plus anciens datent du $\mathrm{V}^{\mathrm{e}} \mathrm{s}$. av. J.-C. ${ }^{35}$; d'autres kourganes célèbres, tel le kourgane d'Or ou celui de Koul-Oba, sont situés sur des éminences rocheuses isolées, le long de la route menant de Kertch à Théodosie ${ }^{36}$. Tous deux se rapportent à une période comprise entre la seconde moitié $\mathrm{du} \mathrm{V}^{\mathrm{e}}$ s. et la première moitié du $\mathrm{IV}^{\mathrm{e}}$ s. av. J.-C. La résurgence d'une telle pratique funéraire dans les premiers siècles de notre ère pourrait donc constituer une forme de référence consciente, dès l'avènement de la dynastie des Tiberii Iulii ${ }^{37}$, à une époque perçue comme prestigieuse et particulièrement prospère dans l'histoire du royaume bosporan.

Les tertres funéraires accueillaient régulièrement d'autres tombes, implantées plus tardivement, comme le suggère du moins le témoignage d'Ašik se souvenant avoir récupéré en 1835 des récipients en verre, des amphores et des lampes de terre cuite, ainsi que des monnaies bosporanes frappées à la fin du III siècle, sous le règne de Sauromatès IV ${ }^{38}$.

33. Voir A. B. Ašik, Kerčenskie drevnosti o pantikapejskoj katakombe, ukrašennoj freskami, chap. V, p. 17.

34. Voir à ce propos F. Gille, Antiquités du Bosphore Cimmérien conservées au Musée impérial de l'Ermitage, p. LXXXVI.

35. Voir en dernier lieu Ju. A. Vinogradov, V. N. Zin'ko, T. N. Smekalova, JuzOba. Kurgannyj nekropol' aristokratii Bospora, T. I. Istorija izučenija i topografija; A. M. Butjagin, Ju. A. Vinogradov, Juz-Oba. Kurgannyj nekropol' aristokratii Bospora. T. II. Kurgany na myse Ak-Burun et la contribution de Ju. A. Vinogradov dans ce volume.

36. Voir pour le kourgane d'Or, V. F. Gajdukevič, «Bosporskie pogrebal'nye sklepy V-IV vv. do n.è. s ustupčatym pokrytiem» et Ju. A. Vinogradov, "Zolotoj kurgan (Altyn-Oba)»; pour Koul-Oba, Ju. A. Vinogradov, «Kurgan Kul'-Oba».

37. Le roi Aspourgos (14 av. J.-C. - 37 apr. J.-C.) est en effet le premier à afficher une titulature acquise sous l'empereur Tibère et se référant explicitement à la dynastie julioclaudienne.

38. Voir A. B. Ašik, Kerčenskie drevnosti o pantikapejskoj katakombe, ukrašennoj freskami, chap. I, p. 2. Il y est fait mention d'un Sauromatès VII dont l'auteur discute le règne dans son ouvrage Vosporskoe Carstvo s ego paleografičeskimi $i$ nadgrobnymi pamjatnikami, raspisnymi vazami, planami, kartami i vidami, vol. I, p. 112, \$76, 
b) L'accès au tombeau

Les investigations ayant abouti, en 1842 , à l'ouverture du tombeau peint sont décrites dans le chapitre V (fort d'une seule page) de l'opuscule d'Ašik: la fouille du kourgane est entamée "à la perpendiculaire de sa base", là où le terrain marque un creux et où le couvert végétal se trouve plus dru. Cette démarche s'avère judicieuse, puisque le rocher, rencontré à moins d'un mètre de profondeur, est travaillé de main d'hommes et révèle une plaque obturant l'entrée de l'hypogée. La perspective d'ouvrir un tombeau inviolé s'estompe à mesure du dégagement de cette plaque, manifestement descellée et ayant laissé de la terre envahir la première salle funéraire. La planche I (Pl. I, p. 230) restitue puits d'accès et entrée dans le tombeau de manière schématique: la façade du tombeau semble taillée au cordeau, la baie de la porte parfaitement équarrie et la chambre funéraire précédée d'un petit corridor d'accès. Le texte d'Ašik n'offre pas davantage de détails et il faut donc se contenter du rendu graphique sommaire dont nous disposons.

La forme du linteau de la porte, arquée, n'est décrite que plus tard, lors de la description des compositions peintes l'encadrant ${ }^{39}$ : elle est haute de 1,65 m, ce que confirme approximativement l'échelle figurant sur la planche III (Pl. III, p. 232) et paraît d'emploi courant dans les constructions funéraires d'époque romaine taillées dans le sous-sol rocheux, comme on le constate par l'exemple d'autres tombeaux à Panticapée (tel le tombeau d'Alkimos fils d'Hègèsippos, celui de 1891, le tombeau d'Anthestèrios ou encore celui découvert en 1872 par Stasov) ou à Nymphaion (la série des caveaux K 4, 11, 12 et 13 datée par N. Grač du $\left.\mathrm{I}^{\text {er }-\mathrm{II}^{\mathrm{e}} \text { siècle }}{ }^{40}\right)$. Sans doute l'arcature vaut-elle pour vestige ou imitation des constructions funéraires maçonnées, avec voûte en plein cintre, et dont l'entrée profitait d'une caractéristique architecturale identique. On en connaît du reste plusieurs exemples à l'époque impériale également (et pour peu qu'il ne s'agisse pas de remploi de monuments plus anciens),

antérieur ou conjoint à celui de Thothorsès. Ce Sauromatès est aujourd'hui désigné sous le nom de Sauromatès IV et son règne n'est assuré que pour l'année 572 de l'ère pontique, correspondant à 275-276 apr. J.-C.

39. A. B. Ašik, Kerčenskie drevnosti o pantikapejskoj katakombe, ukrašennoj freskami, chap. VI, p. 20.

40. Voir N. L. Grač, Nekropol'Nimfeja. 
tel le tombeau sous kourgane ouvert et publié par le même Anton Ašik, dont l'accès à la chambre funéraire se faisait par une entrée arquée et flanquée de pilastres ${ }^{41}$.

c) La structure et les aménagements du tombeau

Le plan et la coupe du tombeau (Pl. I, p. 230 et Pl. II, p. 231) figurent un caveau à deux chambres reliées par un passage également arqué. La première chambre est de plan presque carré $(4,26 \times 4,81 \mathrm{~m})$ avec une hauteur sous plafond atteignant $1,90 \mathrm{~m}$; Ašik reporte une hauteur identique pour la seconde chambre dont les dimensions sont moindres $(3,60$ x 2,96 m ${ }^{42}$. Une banquette est aménagée sur toute la largeur de la première chambre, sans doute maçonnée, à l'instar de ce que l'on pouvait observer dans le tombeau de 1872 décrit par Stasov ${ }^{43}$. Dans la seconde chambre, deux niches étaient taillées dans le registre supérieur de la paroi communicante ${ }^{44}$.

La variété des aménagements internes rend difficile une classification typologique des tombeaux peints de l'«Allée des kourganes" selon l'organisation des lits funéraires et des niches. Rostovcev consacre un bref excursus à cette question au moment de traiter des caractéristiques architecturales du tombeau de $1872^{45}$. La niche de la paroi du fond déciderait ainsi de l'agencement de trois lits funéraires (placés l'un dans la paroi du fond, les deux autres dans les parois latérales), ce dont attesterait encore le

4I. Il est question du fameux «tombeau aux Quatorze cercueils» érigé dans la nécropole tumulaire au nord-est de Panticapée. Sa datation est assurée par une empreinte monétaire sur bandeau funéraire attribué à Antonin le Pieux. Ašik en publie plan et coupe dans le volume II de son Vosporskoe Carstvo s ego paleografičeskimi $i$ nadgrobnymi pamjatnikami, raspisnymi vazami, planami, kartami i vidami (Pl. VI et chap. 41, p. 49 sq.).

42. Voir A. B. Ašik, Kerčenskie drevnosti o pantikapejskoj katakombe, ukrašennoj freskami, chap. V, p. 17.

43. Ces "lits-sarcophages", comme les nomme Rostovcev, sont installés sur les deux côtés du caveau, enduits et peints. Voir M. I. Rostovcev, Antičnaja dekorativnaja živopis' na juge Rossii, p. 295 sq.

44. Voir A. B. Ašik, Kerčenskie drevnosti o pantikapejskoj katakombe, ukrašennoj freskami, chap. VII, p. 34 et Pl. VIII.

45. Voir M. I. Rostovcev, Antičnaja dekorativnaja živopis’ na juge Rossii, p. 296-298. Les lits funéraires du tombeau dit de Stasov, dont Rostovcev identifie de possibles prototypes à l'époque hellénistique tardive, sont rapportés au milieu du $\mathrm{II}^{\mathrm{e}} \mathrm{s}$. apr. J.-C. au plus tard. 
tombeau de 1875 . Il est fort probable que le tombeau de 1842 était également conçu pour abriter trois sépultures: outre la banquette funéraire de la première chambre funéraire, deux sarcophages pouvaient encore prendre place dans la seconde chambre funéraire, là où les planches IX et X (Pl. IX, p. 238 et Pl. X, p. 239) rapportent, à mi-hauteur des parois latérales, une imitation d'opus sectile.

M. I. Rostovcev note une particularité du tombeau dans son plafond, plat et de hauteur constante, qui s'incurve cependant au-dessus de la banquette funéraire ${ }^{46}$. C'est à l'endroit de cette courbure, bien visible sur la coupe du tombeau (Pl. II, p. 231), que se situent des caissons peints, disposés sur deux rangées, et ménageant une transition entre la composition peinte juchant la banquette et le décor du plafond. La répétition de caissons identiques dans leur contenu, mais pas dans leur forme, sur la Pl. VII (Pl. VII, p. 236) revenant au décor du plafond de la première chambre, fait croire à un dédoublement du même décor qui n’a pas lieu d'être: il y a bien dix caissons en tout ${ }^{47}$. Le décor peint des tombeaux de 1872 (dit de Stasov) et de 1875 nous pourvoit à nouveau d'un précieux matériau comparatif. Le plafond du tombeau de 1872 est divisé en quatre secteurs dont trois, celui de la niche principale et ceux situés audessus des lits funéraires, présentent une même division de la surface en caissons imitant des incrustations de marbre ${ }^{48}$. Le plafond plat du corridor menant au tombeau de 1875 est lui aussi orné de caissons peints imitant du marbre, alors que les registres supérieurs des parois sont travaillés en un opus sectile d'apparence bigarrée ${ }^{49}$. Enfin, la voûte en plein cintre du tombeau découvert sur un terrain appartenant au notaire Feldstein (dit "tombeau Feldstein") était sans doute également divisée en caissons peints, dont seuls deux fragments avaient été conservés à l'époque où Rostovcev prenait part à la fouille du monument funéraire ${ }^{50}$.

Les parois des deux chambres du tombeau sont régulièrement scandées de colonnes ioniques au fût lisse. Dans la première chambre, deux

46. Voir M. I. Rostovcev, Antičnaja dekorativnaja živopis’ na juge Rossii, p. 349.

47. Voir A. B. Ašik, Kerčenskie drevnosti o pantikapejskoj katakombe, ukrašennoj freskami, chap. VI, p. 19. La traduction de l'édition Barbet d'Antičnaja dekorativnaja živopis' na juge Rossii (p. 350) induit un redoublement du motif décoratif.

48. Voir M. I. Rostovcev, Antičnaja dekorativnaja živopis' na juge Rossii, p. 308 sq. et Pl. LXXXII.

49. Voir ibid., p. 285 sq. et Pl. LXXV.

5o. Voir ibid., p. 265 et Pl. LXX, 1. 
Fig. 3 - Répertoire de colonnes peintes des monuments funéraires de Kertch : 1. sarcophage de Kertch; 2. tombeau de 1872 (dit de Stasov) ; 3. tombeau de 1875 ; 4. tombeau de 1954 ; 5. tombeau d'Hercule à Anapa; 6. tombeau de 1842 (dit d'Ašik). Infographie de D. Glauser (C) UNIL/IASA.

parois en sont pourtant dépourvues, celle d'entrée et celle accueillant la banquette funéraire. Dans la seconde chambre, la paroi d'entrée compte deux colonnes s'arrêtant à mi-hauteur, en raison de la présence de deux niches creusées dans le registre supérieur. On notera que la Pl. I (Pl. I, p. 230) de l'opuscule d'Ašik n'indique pas la présence d'aménagement de niches dans l'épaisseur de la paroi, comme elle ne signale pas le relief des colonnes. Faut-il en conclure que les colonnes n'étaient que peintes? Un décor sculpté ou moulé paraît peu probable dans le contexte des tombeaux bosporans. Les exemples de "colonnades» dont nous disposons en milieu funéraire, tel le sarcophage de Kertch, le tombeau de 1872 (dit de Stasov), celui de 1875 ou encore celui du tombeau d'Hercule à Anapa (fig. 3), témoignent en faveur d'un rendu purement pictural, et non plastique, de cette division architecturale de l'espace ${ }^{51}$. Les investigations réalisées sur le site de General'skoe Zapadnoe, un établissement agricole installé sur la façade azovienne de la péninsule de Kertch, ont toutefois permis de documenter des tombeaux aux parois ornées de pilastres en relief. Hauts de près de $80 \mathrm{~cm}$ et larges de $40 \mathrm{~cm}$, ces piliers séparaient des niches en arcosolium et formaient une légère saillie de $5 \mathrm{~cm}^{52}$.

5I. Le texte d'Ašik, Kerčenskie drevnosti o pantikapejskoj katakombe, ukrašennoj freskami, chap. VI, p. 22, ne mentionne pas de décor en stuc.

52. A. A. Maslennikov, Semejnye sklepy sel'skogo naselenija pozdneantičnogo Bospora, p. 5 sq., évoque deux tombes pareillement aménagées, pillées, à la construction rapportée au dernier tiers du III ${ }^{\mathrm{e}}$ s. apr. J.-C. 
Si elles sont curieusement privées de base, les colonnes peintes du tombeau de 1842 reposent à même un soubassement rouge haut de $26 \mathrm{~cm}$ qui court invariablement au bas des parois des deux chambres funéraires. Elles soutiennent une corniche ionique à l'économie particulière, puisque l'architrave et la frise en sont absentes. Un rang d'oves et de fers de lance pointés est immédiatement surmonté de quatre fasces colorées et marque ici le départ du plafond que la corniche feint soutenir. Cette dernière est apprêtée différemment dans la seconde chambre où elle est complétée d'un rang de $S$ couchés, alors que seule une fasce subsiste sous le plafond.

\subsection{Le mobilier archéologique}

Les trouvailles opérées dans le tombeau de 1842 sont énoncées de manière très laconique par Ašik, ce que regrette Rostovcev en dénonçant l'absence de tout relevé dans le rapport remis à Saint-Pétersbourg. On apprend ainsi que des tessons de céramique et des bris de verre ont été remarqués dans les deux chambres funéraires ${ }^{53}$. Aucune mention n'est faite ni d'ossements ni de vestiges de sarcophages en bois. L'intérêt du directeur du muséum était tout entier porté vers les objets précieux qu'il pourrait remettre à l'Empereur: c'est pourquoi Ašik déplore le pillage d'une tombe qui aurait pu produire, outre ses peintures, «une remarquable acquisition d'antiquités».

\section{La publication du tombeau}

Annonciateur d'une publication circonstanciée et illustrée du tombeau peint découvert en 1842, un court article de la plume d'Anton Ašik intitulé sobrement «Kerčenskie katakomby» [Les catacombes de Kertch»] paraît à Saint-Pétersbourg dans une livraison du Journal du Ministère de l'Intérieur de $1845^{54}$. L'auteur s'y met en scène de manière avantageuse, se présentant en homme de terrain expérimenté et affirmant avoir mis

53. Voir A. B. Ašik, Kerčenskie drevnosti o pantikapejskoj katakombe, ukrašennoj freskami, chap. V, p. 17 et M. I. Rostovcev, Antičnaja dekorativnaja živopis' na juge Rossii, p. 349.

54. Voir A. Ašik, «Kerčenskie katakomby». 
au point une méthode originale de détection des tombes sous kourgane. Ouvrant ainsi de nombreux hypogées creusés dans le sous-sol de Kertch, Ašik décrit de véritables réseaux de tombes et les compare aux "grottes funéraires» découvertes plus tôt en Étrurie. Les monuments funéraires de Russie méridionale valent bien ceux d'Italie, comme le laisse supposer son texte émaillé de références aux "grotti" étrusques mis au jour non loin de Tarquinia ${ }^{55}$.

L'invention du tombeau de 1842 laisse incrédules les savants d'Italie et d'Allemagne auxquels Ašik montrera les dessins des compositions peintes lors de ses voyages en Europe occidentale. Un style «mi-grec, mi-étrusque» est dès lors assigné à ces peintures et la palette des couleurs répertoriées à Kertch est à nouveau confrontée à celles des tombeaux étrusques ouverts à Tarquinia, ce qui doit renforcer le lectorat de la capitale impériale russe dans son impression de détenir, avec les terres conquises sur les Ottomans à la fin du XVIIIe siècle, un héritage patrimonial antique de premier plan, comparable à celui d'Italie ou de Grèce ${ }^{56}$.

La parution de ce texte, présenté comme l'extrait d'un ouvrage sur le thème des catacombes de Kertch, anticipe donc la sortie de presse de l'opuscule d'Ašik pour mieux éveiller la curiosité et appâter d'éventuels lecteurs, curieux des fouilles réalisées à Kertch et des résultats flatteurs qu'elles produisent.

55. Dans un article intitulé «La découverte des Étrusques au début du XIX ${ }^{\mathrm{e}}$ siècle», Jacques Heurgon énumère la mise au jour inattendue, entre 1827 et 1833, des plus belles tombes peintes de Corneto Tarquinia, les célèbres grotti: «Et coup sur coup, en l'espace de moins de six ans, une dizaine des plus belles tombes allaient être découvertes. En 1827 la tombe de la Mer, la tombe des Inscriptions, la tombe du Baron, la tombe des Biges; en 1830 la tombe du Triclinium; en 1831 la tombe Querciola; en 1832 la tombe du Mort et la tombe du Typhon; en 1833 la tombe Giustiniani et la tombe de la Truie noire» (p. 595).

56. Voir A. Ašik, «Kerčenskie katakomby», p. 407. 
3.1. «Les Antiquités de Kertch. Sur une catacombe peinte de Panticapée»

S'il est dédicacé à Mikhail Voroncov, général-gouverneur de Nouvelle Russie et Bessarabie revêtu en 1845 du titre de prince ${ }^{57}$, l'ouvrage rédigé par Anton Ašik paraît à compte d'auteur. L'investissement consenti grève considérablement les finances du directeur du muséum de Kertch, ce dont témoigne régulièrement la correspondance échangée avec SaintPétersbourg. Car les souscriptions se révèlent insuffisantes pour écouler les exemplaires imprimés et la rentabilité de l'entreprise est donc compromise ${ }^{58}$.

Ces circonstances défavorables ont-elles entraîné un retard dans l'impression de l'ouvrage? Car la diffusion de l'opuscule d'Ašik ne semble pas intervenir immédiatement après sa parution, en $1845^{59}$. Qu'il faille imputer cet éventuel contretemps à un facteur technique - un délai plus ou moins long s'écoulant entre la remise du manuscrit et la production de l'ouvrage - ou à une mésentente avec l'imprimeur, on notera que la première recension de l'ouvrage, de la plume de Bernhard von Köhne, ne paraît qu'en juin 1847, tandis que les correspondants d'Ašik ne le mentionnent pas avant le mois de mai de cette même année ${ }^{60}$.

57. Voroncov est fait prince par le Tsar à la suite de la prise de Dargo, le fief du chef de guerre Chamil, en juillet 1845 .

58. L'ouvrage ne porte pas mention du tirage, mais il paraît vraisemblable de porter le nombre d'exemplaires imprimés à 300 au maximum, attendu que B. von Köhne l'invite à en produire un extrait en français à 150, voire 200 exemplaires (lettre du 21.05.1849 conservée à IRLI, f. 615, ed. khr. 14, feuillets 5 à 6 [verso]).

59. L'impression du manuscrit a été confiée à la typographie A. Braun, à Odessa. L'ouvrage porte, en couverture, l'indication de l'année 1845. Les trois volumes composant le prochain ouvrage d'Anton Ašik, Vosporskoe Carstvo s ego paleografičeskimi i nadgrobnymi pamjatnikami, raspisnymi vazami, planami, kartami i vidami, seront confiés à la typographie Nejman et Cie à Odessa.

6o. Voir la recension de B. von Köhne dans la revue Finskij vestnik [Le messager de Finlande] de juin 1847, p. 26-31. Dans une lettre datée du 2 mai 1847 (publiée dans les Izvestija Imperatorskogo Russkogo arkheologičeskogo obščestva [Bulletins de la société impériale russe d'archéologie] 8, vyp. 5, 1877, col. 555), Grigorij Spasskij remercie Ašik de lui avoir fait parvenir l'ouvrage en cadeau. 


\subsection{L'économie de l'ouvrage}

L'ouvrage est long d'une quarantaine de pages réparties en sept chapitres; il est en outre coiffé d'une introduction de trois pages, se clôt sur une conclusion de quatre pages et compte douze planches en noir et blanc rassemblées en fin d'ouvrage. M. I. Rostovcev relèvera ultérieurement que la majorité des ouvrages mis en vente n'était pas coloriée ${ }^{61}$.

Introduction. Ašik se positionne comme un «antiquaire» dont «les opinions", si elles ne sont pas irréprochables, confesseraient cependant un sens critique aigu en s'appuyant tant sur l'existence de données positives que sur un matériau comparatif pertinent. Le directeur du muséum de Kertch se réfère ainsi d'entrée aux travaux et à l'autorité de savants tel Johann Winckelman, les étruscologues italiens Luigi Lanzi, Mario Guarnacci et Anton F. Gori ou encore l'emblématique comte de Caylus, auteur d'un imposant "Recueil d'antiquités égyptiennes, étrusques, grecques et romaines", comme pour donner à son propos une patine érudite - ce dont il lui sera fait reproche, notamment de la part de Rostovcev qui dénonce "un vernis d'érudition» ${ }^{62}$.

Pétition à peine voilée à l'adresse du gouverneur de Kertch-Iénikalé, du général-gouverneur de Nouvelle Russie et Bessarabie et des cercles savants de Saint-Pétersbourg en faveur des "richesses historiques» que recèlent les terres de Crimée, du Caucase et de la province de Nouvelle Russie tout entière, l'opuscule consacré aux "catacombes» de Kertch et à la découverte de 1842 doit servir à illustrer et magnifier les antiques dont regorgeraient Kertch et sa région, à rehausser le prestige de Panticapée et Phanagorie et leur permettre ainsi de rivaliser avec les découvertes faites en Italie. Mais en attendant que les fouilles aient livré de grands ensembles de ruines pareilles à ceux de Rome, Ašik se propose d'examiner la découverte "de la catacombe avec fresques".

Chapitre I "Sur les catacombes païennes antiques en général». Hors quelques menus aménagements, le texte publié dans ce chapitre reproduit

6I. Voir M. I. Rostovcev, Antičnaja dekorativnaja živopis’ na juge Rossii, p. 349: «[...] en tout cas, dans toute une série d'exemplaires mis en vente (mais pas tous, tant s'en faut), les planches étaient coloriées à la main ».

62. Voir M. I. Rostovcev, Antičnaja dekorativnaja živopis’ na juge Rossii, p. 7: «Les rapports de A. B. Ašik, beaucoup plus superficiels - l'auteur voulant y briller d'une science illusoire - sont parfois rehaussés par les excellents dessins de son collaborateur K. R. Begičev». 
exactement celui de l'article paru plus tôt dans le Journal du ministère. Ašik livre une vision pittoresque des tombeaux qu'il visite, cédant par moment à une forme de sensationnalisme scabreux lorsqu'il évoque "l'horreur mystérieuse» qui l'étreint lors de ses explorations. Mais sans doute cette expérience, enveloppée d'un nimbe quasi mystique, est-elle l'apanage de ces "antiquaires" au nombre desquels Ašik se range luimême ${ }^{63}$. Et, s'il se pose à tort en inventeur des catacombes de Kertch, toutefois obtient-il de sa hiérarchie de pouvoir consulter des savants italiens et allemands et leur montrer les dessins reproduisant les compositions peintes du tombeau. L'attribution à un style pictural, "grec", et l'appréciation chronologique du monument peint, "le début de notre ère", reflètent les préoccupations classificatoires de la société savante de l'époque, de même que son intérêt pour les couleurs des compositions peintes et la fidélité de leur rendu sur une reproduction graphique qu'Anton Ašik présente comme étant un "fac-similé».

Chapitre II "Des catacombes chrétiennes de Rome». S'il ne contient rien qui concerne l'hypogée de Kertch, ce chapitre se réfère au voyage de Rome qu'entreprit Ašik et condense autour des catacombes chrétiennes et du Colisée les impressions teintées de piété et de bonne morale du voyageur venu de Russie méridionale. L'auteur veut apparaître en "connaisseur» des catacombes romaines et de ses récents interprètes, tel Désiré Raoul-Rochette, dont il cite un ouvrage sur le sujet ${ }^{64}$.

Chapitre III "Essai sur la peinture des anciens». Pour prétentieux qu'en soit le titre, ce chapitre de deux pages cherche surtout à réhabiliter la peinture antique au terme d'un développement passablement décousu. La peinture antique aurait atteint un degré de perfection égal à la sculpture, illustré notamment par le tombeau des Nasonii à Rome ou la Maison du Faune à Pompéi, fouillée entre 1830 et 1832. Ašik évoque pêle-mêle des monuments peints qu'il aura certainement visités sans comprendre cependant leur place dans l'histoire de l'art pictural. Il s'en remet in fine à un passage de Pline l'Ancien pour qui «le déclin de cet art» intervient durant le siècle d'Auguste. Les catacombes de Kertch,

63. On trouve encore exprimée, un peu plus loin sur la même page, une des caractéristiques, romantiques, partagées par les "antiquaires»: celle de percevoir «le battement d'ailes du souffle éternel de la vie».

64. Sans doute le Tableau des catacombes de Rome, paru en 1837 auprès de la Bibliothèque universelle de la jeunesse, à Paris. 
note-t-il alors, s'inscrivent toutes dans cette période, ce que confirmeraient notamment les trouvailles monétaires. Les peintures du tombeau ouvert en 1842 sont même situées plus précisément à l'époque antonine, au moment où la peinture pariétale connaîtrait déjà son crépuscule.

Chapitre IV "Sur diverses représentations peintes sur des monuments et des tombes antiques». Plus longue digression introductive avant la description du tombeau et de ses compositions peintes, ce chapitre s'appuie sur des considérations "universalistes» inspirées des écrits d'antiquaires du siècle précédent pour parer à l'embarras que suscite la rareté des monuments funéraires peints d'époque romaine connus de l'auteur. Ašik adhère en effet à l'idée que les civilisations antiques héritaient les unes des autres dans un processus assurant au christianisme une prééminence logique, historique et morale, sur les communautés païennes ${ }^{65}$. La religion romaine intégrait ainsi de nombreux éléments d'autres cultures, ce dont le royaume du Bosphore Cimmérien faisait la démonstration, croyait savoir Ašik, avec la découverte d'une inscription de la reine Komosaryè mentionnant des divinités orientales ${ }^{66}$. De la sorte, il ne paraissait pas étrange que le tombeau de 1842 reflétât des traits de la religion égyptienne dans ses compositions peintes (sans qu'ils soient toutefois détaillés)! Les antiquités qu’Ašik découvre au musée archéologique de Pérouse servent encore de matériau de comparaison dans l'interprétation fournie à plusieurs scènes du tombeau de Kertch. Ainsi, les urnes cinéraires peintes et les peintures des tombeaux étrusques produisent un abondant répertoire de scènes de chasse, de combats ou de prestations musicales faisant écho aux compositions peintes du tombeau de Kertch. Pareils rapprochements, pour hétéroclites qu'ils soient, trouvent une validation apparente dans la démarche globalisante entreprise par le célèbre philologue allemand F. Creuzer dans son ouvrage La symbolique et la mythologie des peuples anciens ${ }^{67}$.

65. Cette vision de l'histoire ancienne, regroupant les «grandes civilisations» du bassin méditerranéen, trouve une formulation canonique dans l'œuvre du comte de Caylus.

66. Sanergès et Astarté sont les divinités auxquelles la reine dédie un groupe statuaire dont le socle inscrit est mis au jour sur le rivage du liman Akhtanizovskoe, sur la presqu'île de Taman (CIRB 1015).

67. Traduite en français par J.-D. Guigniaut dès 1821, l'œuvre de F. Creuzer, Symbolik und Mythologie der alten Völker, besonders der Griechen, parue à Leipzig/ Darmstadt chez C. W. Leske en 1810-1812, a marqué son époque et suscité de nombreuses controverses. 
Chapitre V "Description de la catacombe" et chapitre VI "Description des fresques». Les deux chapitres constituent le cœur de l'opuscule d'Ašik puisqu'ils font office de commentaire et de descriptif des planches, renseignant, pour l'un, les dimensions et les caractéristiques architecturales du monument funéraire, pour l'autre, la teneur et les couleurs des compositions peintes.

Chapitre VII "Explications des dessins de la première et de la seconde chambre funéraire». La partie interprétative de l'ouvrage, si elle témoigne d'un intérêt sincère d'Anton Ašik pour l'Antiquité gréco-romaine, prête singulièrement le flanc à la critique tant elle manifeste le dilettantisme, voire la naïveté de l'auteur dans les questions d'érudition. Les comparaisons avec le monde contemporain, à l'exemple de celles risquées avec des coutumes attribuées au Caucase ou avec des préparations culinaires françaises, sont parfois déconcertantes. Les tentatives d'Ašik visant à identifier le défunt et sa conjointe font en revanche la preuve d'un réel effort de compréhension des compositions peintes. La notion de "symbole" apparaît à plusieurs reprises (appliquée notamment aux végétaux peints) et traduit une sensibilité de l'auteur aux questions d'iconographie ${ }^{68}$. La littérature moderne - il cite notamment le prolifique Ennio Quirinio Visconti - comme les textes antiques (souvent mentionnés pêle-mêle) sont sollicités à l'appui de son discours. Les compositions peintes du tombeau des Nasonii, à Rome, jouissent toujours d'une grande réputation grâce aux reproductions en couleurs qu'en publièrent G. P. Bellori et P. S. Bartoli ${ }^{69}$ - Ašik opère sur cette base un rapprochement avec la représentation de l'enlèvement de Perséphone présente dans le tombeau de 1842 et identifie des attributs dionysiaques dans les peintures des deux hypogées.

Conclusion. Contre toute attente, la partie conclusive de l'opuscule est dénuée de tout rapport avec le monument funéraire ouvert en 1842! Anton Ašik y évoque un essai de sa plume portant sur les antiquités de Kertch et confié pour publication à F. Gille dans le cadre de travaux

68. Quoiqu'elle mène aussi à des incongruités. Ašik interprète ainsi les cercles peints sur les plafonds comme les représentations de la lune et du soleil, alors qu'ils figurent certainement des couronnes.

69. Voir à ce propos la thèse de D. Burlot, Peintures romaines antiques et faussaires, passim. 
éditoriaux menés à Saint-Pétersbourg ${ }^{70}$. Il revient ensuite longuement sur l'inscription mentionnant Komosaryè - document unique nous informant pour la première fois, précise-t-il, de la titulature des rois du Bosphore Cimmérien. Cette ultime digression conduit l'auteur à traiter de la composition ethnique du royaume et à envisager les populations sindes et méotes dans leur rapport à l'autorité d'un souverain étant également à la tête d'un État hellénique.

\section{Le relevé des peintures}

Dans son ouvrage consacré au tombeau de 1842, Anton Ašik souligne la priorité qu'il accorde d'emblée aux compositions peintes mises au jour. Il dit en avoir réalisé immédiatement "un véritable fac-similé», aidé dans sa tâche par Stefanskij, un dessinateur au service du muséum de Kertch. Le processus de copie des peintures aurait duré trois jours, ce qui paraît extrêmement rapide compte tenu de l'ampleur de la tâche et des difficultés techniques qu'elle induit. Pareil délai contredit en outre le contenu de la lettre du 18 mars 1842 adressée au prince Kherkeulidzev, gouverneur de Kertch (supra, p. 186). L'insistance d'Ašik qui déclare avoir reproduit scrupuleusement, "jusque dans les moindres détails", les peintures de l'hypogée suscite toutefois la méfiance: le directeur du muséum a-t-il pu relever avec suffisamment de soin et en un délai si court des compositions peintes nombreuses et relativement complexes? Ces dernières ont-elles été reproduites à l'échelle, par la technique du calque, ce que voudrait signifier le terme de "fac-similé»? Quelle est l'implication de Stefanskij dans la facture de ce travail?

Nous ignorons quel procédé a été initialement retenu et quel en a été le résultat, de même nous ignorons si cette reproduction a servi de base aux dessins coloriés publiés dans l'ouvrage de 1845 avec le descriptif des compositions peintes. L'intervention de Stefanskij demanderait également à être authentifiée et quantifiée. C'est pourtant à ce dernier que M. I. Rostovcev attribue les dessins en couleur du tombeau qui auraient

70. Ce projet éditorial devait s'achever en 1854 avec la parution à Saint-Pétersbourg des fameuses Antiquités du Bosphore Cimmérien qui n’intégreront finalement pas le manuscrit remis par Ašik. 
servi de support à Ašik pour en rédiger la description ${ }^{71}$. Comment expliquer pareille allégation de la part du savant pictorialiste? En réalité, le texte de l'ouvrage évoque une reproduction des compositions peintes réalisée dans un format aisément transportable. Anton Ašik déclare en effet avoir montré les dessins de la catacombe à beaucoup d'archéologues allemands et italiens ${ }^{72}$. On comprendra par-là, avec Rostovcev, que des reproductions du tombeau de 1842 ont fait le voyage de l'Autriche et de l'Italie où Ašik se rendit en mission pour y consulter des savants et y découvrir le patrimoine antique. Il paraît donc probable que les dessins de l'opuscule de 1845 soient ceux présentés en voyage et qu'ils soient tirés du fameux «fac-similé» dont la trace s'est perdue.

À en croire Ašik, il semble que l'état des peintures, décrites comme "très fraîches» et quasi intactes, se soit très vite détérioré. Au lendemain de l'ouverture du caveau funéraire, les premières traces de dégradation étaient déjà repérées, ce qui aura sans doute eu des conséquences également sur le processus de relevé des peintures et, inévitablement, sur la qualité de la reproduction ${ }^{73}$. La palette chromatique que dresse Anton Ašik (une gamme de couleurs comprenant du blanc, noir, rouge, jaune, bleu, vert et gris) lors de l'ouverture de l'hypogée doit convaincre tant de l'importance du monument funéraire de Kertch que du bien-fondé de la démarche.

Si M. I. Rostovcev doutait de la qualité des dessins publiés par Anton Ašik en 1845, ignorant volontairement un descriptif qu'il considérait comme vicié (Ašik n'aurait pas décrit le tombeau et ses compositions peintes sur place), il ajoutait cependant un certain crédit aux indications des couleurs fournies par le directeur du muséum. Il chercha également à se procurer plusieurs exemplaires coloriés de l'opuscule pour en vérifier la qualité et la similitude dans le rendu chromatique du coloriage:

Les relevés de Stefanskij avaient été faits en couleur; en tout cas, dans toute une série d'exemplaires mis en vente (mais pas tous, tant s'en faut), les planches étaient coloriées à la main, de manière plus ou moins

7I. Voir M. I. Rostovcev, Antičnaja dekorativnaja živopis' na juge Rossii, p. 350.

72. Voir A. B. Ašik, Kerčenskie drevnosti o pantikapejskoj katakombe, ukrašennoj freskami, chap. I, p. 3.

73. Voir ibid., chap. I, p. 4. 
identique partout. Ma description et la reproduction des différentes scènes sur les planches partent de l'un de ces exemplaires coloriés ${ }^{74}$.

Comment se fait-il alors que l'atlas de planches de Antičnaja dekorativnaja živopis' na Juge Rossii [La peinture décorative antique en Russie méridionale] n'ait pas contenu de reproductions des dessins coloriés? Qu'elle qu'en soit la raison, intentionnelle ou contrainte (pour motif technique ou financier), les dessins coloriés du tombeau découvert par Ašik en 1842 sont restés inconnus de la communauté scientifique jusqu’à aujourd'hui. Nous en avons retrouvé deux exemplaires conservés dans les bibliothèques de musées renommés.

\subsection{Les éditions coloriées}

a) L'édition du Musée russe d'Ethnographie

La découverte d'une édition coloriée de l'ouvrage d'Ašik à la bibliothèque du Musée russe d'Ethnographie de Saint-Pétersbourg est l'aboutissement d'une petite enquête suggérée, à près d'un siècle d'intervalle, par Vjačeslav Škorpil dans une lettre de 1913 adressée à M. I. Rostovcev et dont nous proposons ici la traduction:

Cher Mikhail Ivanovič,

Je vous envoie ici les corrections. N. I. Repnikov était récemment de passage à Kertch et m’a dit qu'il disposait d'un exemplaire d'Ašik «Sur les catacombes de Panticapée décorées de fresques» dans lequel les dessins étaient coloriés. À en juger d'après sa reliure luxueuse, Repnikov suppose que cet exemplaire était destiné à quelque personnage important et que, peut-être, il fut colorié par Stefanskij dans la catacombe même ${ }^{75}$.

Tout entier occupé à la rédaction de son ouvrage sur la peinture antique en Russie méridionale, Rostovcev cherchait manifestement à obtenir une édition coloriée de l'ouvrage d'Ašik qui lui faisait encore défaut pour la

74. Voir M. I. Rostovcev, Antičnaja dekorativnaja živopis’ na juge Rossii, p. 349, traduction française de l'édition Barbet.

75. Voir Archives de l'Académie des sciences de Russie siège de Saint-Pétersbourg, F. 1054 (Rostovcev), op. 1, ed. khr. 18 - lettre de V. V. Škorpil à M. I. Rostovcev. 


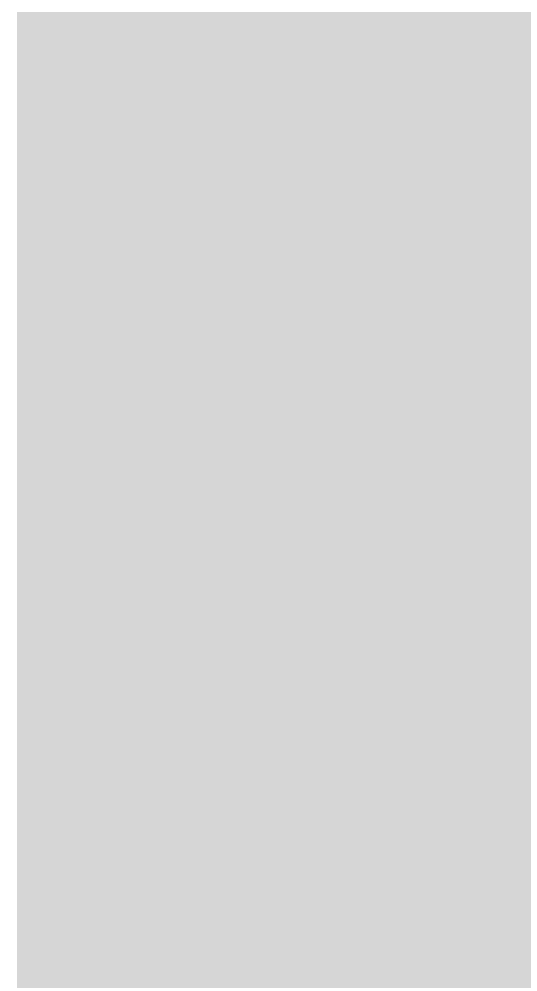

Fig. 4 - Portrait de Nikolaj Ivanovič Repnikov d'après une photographie de 1907 conservée dans les Archives scientifiques de l'Institut d'histoire de la culture matérielle ( $\mathrm{N}^{\circ}$ inv. Q. 455.62). (C) Archives scientifiques de l'Institut d'histoire de la culture matérielle, Saint-Pétersbourg. rédaction du chapitre correspondant. On peut donc en déduire que le savant en disposa dans les derniers mois précédant la remise du manuscrit à la typographie. Il précise en effet dans son ouvrage avoir eu plusieurs éditions coloriées entre les mains pour documenter son chapitre et en avoir vérifié la concordance chromatique ${ }^{76}$.

Qui est donc ce Repnikov que mentionne Vjačeslav Škorpil? (fig. 4) Archéologue aux multiples facettes, Nikolaj Ivanovič Repnikov (1882-1940) connaît très bien la Russie méridionale, la Crimée en particulier, qu'il parcourt sa vie durant et dont il documente autant le patrimoine archéologique que les us et coutumes des diverses ethnies. Il est notamment connu pour avoir mis au jour la nécropole gothe de Suuk-Su et a pris part aux fouilles de la nécropole d'Olbia placées sous la direction de Boris Farmakovskij. Nikolaj Repnikov profite déjà d'une solide expérience de terrain lorsqu'il initie encore, au pied du mont Aju-Dag, l'exploration archéologique de la basilique paléobyzantine de Parthénite, en 19071908. Il est ensuite engagé par le département ethnographique du Musée Russe qui deviendra plus tard une entité autonome instituée en "Musée Ethnographique». C'est à l'enseigne de ce musée que Repnikov se voue à la fouille de Staraja Ladoga, puis de Novgorod, jetant son dévolu sur

76. Voir M. I. Rostovcev, Antičnaja dekorativnaja živopis’ na juge Rossii, p. 349. 
l'étude du patrimoine en bois de l'ancienne Russie, traitant également de la peinture d'icônes et des compositions peintes des églises ${ }^{77}$.

Le parcours professionnel de Repnikov justifiait de se renseigner sur l'existence éventuelle d'un exemplaire colorié déposé ailleurs qu'à la bibliothèque de l'Institut d'histoire de la culture matérielle à SaintPétersbourg où le "fonds Repnikov", riche de 450 entrées, ne comptait aucun des ouvrages publiés par Anton Ašik. Il fallait identifier une autre bibliothèque institutionnelle susceptible d'avoir recueilli une partie de la collection de notre archéologue, dont l'ouvrage tant convoité que mentionnait Škorpil. Notre intuition allait se vérifier à l'occasion d'un séjour à Saint-Pétersbourg: il existait bien un "fonds Repnikov» auprès de la bibliothèque du Musée russe d'Ethnographie! Qui plus est, ce fonds contenait toutes les publications d'Anton Ašik, dont des tirés à part de ses articles parus dans la Journal du Ministère de l'Intérieur.

Parmi ces ouvrages figure un exemplaire colorié des Kerčenskie drevnosti [Antiquités de Kertch] muni du sceau de la bibliothèque du Musée Russe Alexandre III! ${ }^{78}$ Vierge de toute annotation permettant d'en identifier le propriétaire initial, l'édition du Musée russe d'Ethnographie était sans doute destinée à un personnage de haut rang, peut-être le mystérieux baron auquel était adressée une lettre insérée dans la première partie de Vosporskoe Cartsvo [Le Royaume du Bosphore]. Car la présence groupée de tirés à part et d'ouvrages du même auteur donne l'impression non seulement d'une unité propre à une collection, mais encore d'une proximité entre leur propriétaire et Anton Ašik, ce que confirmerait la présence d'un courrier privé retrouvé dans l'un des ouvrages ${ }^{79}$.

77. Ces renseignements biographiques sont tirés de A. N. Bernštam, S. N. Bibikov, «N. I. Repnikov (1882-1940). Nekrolog»; V. I. Ravdonikas, «Pamjati N. I. Repnikova»; G. V. Dlužnevskaja, M. V. Medvedeva, N. I. Platonova, A. E. Musin, «Slavjano-russkie i srednevekovye drevnosti v issledovanijakh imperatorskoj arkheologičeskoj komissi", p. 871.

78. Il porte la cote I.D. 226. Je remercie Valentina Vladimirovna Gavrišina, collaboratrice scientifique au Musée russe d'Ethnographie, de son aimable concours, ainsi que Natalja Nikolaevna Prokop'eva, conservatrice en chef, d'avoir autorisé mes investigations au sein du musée.

79. À ce stade de notre enquête, les modalités d'acquisition des ouvrages d'A. B. Ašik déposés dans la bibliothèque du musée n’ont pas été totalement élucidées. Nous supposons donc qu'ils ont été acquis en bloc par N. I. Repnikov qui les aura légués ou revendus au «département d'ethnographie du Musée Russe». 
Ce sont les planches coloriées des Kerčenskie drevnosti [Antiquités de Kertch] déposées dans la bibliothèque du Musée russe d'Ethnographie qui ont été choisies pour être reproduites dans cet article (voir l'annexe des planches, p. 229-241).

\section{b) L'édition du Musée des Beaux-Arts de Iaroslavl}

Le centenaire de la naissance de Viktor Vladimirovič Ašik, un petit-fils d'Anton Baltazarovič, allait donner lieu à une rétrospective inédite de ses collections d'art dans trois villes de Russie. À Saint-Pétersbourg, c'est le palais Roumiantsev, sur le quai des Anglais, qui accueillit la manifestation durant quelques semaines de l'hiver 2005-2006. S'il ne répertoriait aucune pièce antique, le catalogue d'exposition nous mettait du moins sur la piste d'un des descendants d'Anton Ašik, collectionneur averti de surcroît, ce qui laissait présager un rebondissement favorable à notre quête d'un exemplaire colorié des Kerčenskie drevnosti [Antiquités de Kertch] ${ }^{80}$. Acquises en plusieurs lots successifs par le Musée des BeauxArts de Iaroslavl, les collections de feu Viktor Vladimirovič étaient donc conservées et exposées dans cette ville de l'Anneau d'or située à $300 \mathrm{~km}$ au nord-est de Moscou. Un intervalle de douze ans nous séparait de l'opportunité, qui se présenta enfin à l'automne 2018, de nous rendre à Iaroslavl pour y explorer l'héritage de la famille Ašik.

Le musée des Beaux-Arts de Iaroslav avait fait l'acquisition, dès 1985, des collections constituées par deux générations d'Ašik, que le dernier représentant de la famille, Viktor Vladimirovič, ingénieur maintes fois décoré et professeur émérite de l'Institut de construction navale de Leningrad, accumulait dans un appartement de trois pièces, faisant l'impression «d'un musée de la vie quotidienne de l'aristocratie russe du

80. Après Moscou et Iaroslavl, l'exposition dévolue plus spécifiquement aux aquarelles et dessins issus des collections de V. V. Ašik se tint entre novembre 2005 et janvier 2006 à Saint-Pétersbourg, dans quelques salles du palais érigé par le comte Roumiantsev, aujourd'hui institué en filiale du Musée d'histoire de Saint-Pétersbourg. Nous devons à Irina Vladimirovna Tunkina, directrice des Archives de l'Académie des sciences de Russie, siège de Saint-Pétersbourg, d'être à l'initiative de cette visite. Le catalogue d'exposition, consacré aux collections du Musée des Beaux-Arts de Iaroslavl, est paru dans la série des Šedevry muzejnykh kollekcij [Chefs-d'œuvre des collections muséales] publiée par l'École de l'aquarelle de Sergej Andrijaka, à Moscou. 


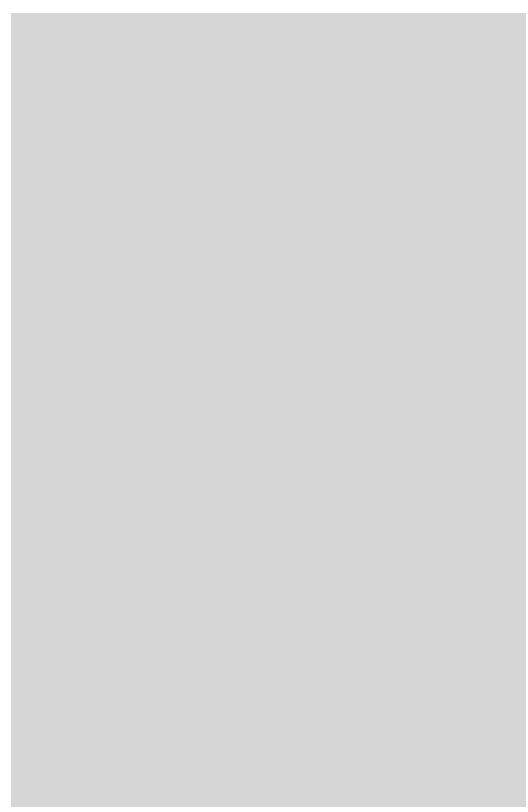

Fig. 5 - Portrait silhouette d'Anton Baltazarovič Ašik, découpé et collé sur papier. (C) Musée et Parc historico-culturel de Crimée orientale, Kertch ( $\mathrm{N}^{\circ}$ inv. F.1849).

XVIII ${ }^{\mathrm{e}}$ au début du XX $\mathrm{XX}^{\mathrm{e}}$ siècle» ${ }^{81}$. Cet ensemble extraordinaire, comprenant plusieurs milliers œuvres d'art, 8000 livres et des archives familiales, représentait un accroissement inespéré pour le musée de Iaroslavl dont l'inventaire doubla d'un seul coup.

Les archives familiales n'ont gardé hélas qu'un maigre souvenir d'Anton Baltazarovič (bien qu'elles contiennent des documents datables de 1799 aux années 1980) : un portrait silhouette, légué dans les années 1960 par Viktor Vladimirovič au Musée historicoculturel de Kertch (fig. 5) ${ }^{82}$, et un portrait photographique de sa femme, Anna Aleksandrovna ${ }^{83}$. Elles retracent essentiellement le parcours de Viktor Vladimirovič et de son père. C'est à ce dernier que l'on doit d'avoir initié une collection artistique reflétant des intérêts multiples. On sait d'Anton Baltazarovič qu'il jeta les bases de la collection familiale dont il fit présent, pour une partie importante, au muséum de Kertch dont il avait la charge. Sa collection de monnaies antiques intégra les médailliers du musée, tandis que des livres en sa possession fondèrent la bibliothèque de la nouvelle institution. La bibliothèque acquise par le musée de Iaroslavl

8I. Voir à ce propos l'introduction de L. L. Jurova et l'article de N. O. Konovalova, "Ašiki - dinastija kollekcionerov", ainsi que le témoignage de V. K. Korčenov, lié d'amitié à V. V. Ašik.

82. Voir L. M. Lazenkova, Kerčenskij muzej drevnostej, p. 20, n. 68. Je remercie Natal'ja Valdimirovna Bykovskaja, vice-directrice du Musée et Parc historico-culturel de Crimée orientale, à Kertch, de sa précieuse collaboration.

83. Photographie de Anna Aleksandrovna Ašik dédicacée à son fils Vladimir, voir L. L. Jurova (otv. red.), Semejnoe prizvanie. Kollekcii Ašikov, p. 120, n 422 (= Archives scientifiques du Musée des Beaux-Arts de Iaroslav, F. 50, op. 1, D. 222/47). 


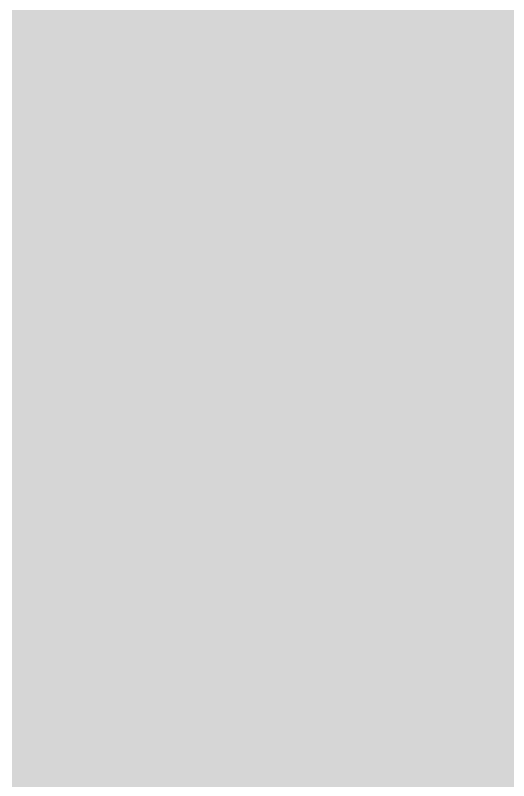

Fig. 6 - Ex-libris du bouquiniste Vasilij Ivanovič Kločkov, Saint-Pétersbourg.

(C) Musée des Beaux-Arts de Iaroslavl. ne comptait toutefois qu'un seul ouvrage assurément acquis par Anton Ašik: un album de gravures de Fjodor Petrovič Tolstoj datant de la première moitié du $\mathrm{XIX}^{\mathrm{e}}$ siècle ${ }^{84}$.

N'y avait-il donc aucune trace, à Iaroslavl, des livres écrits et publiés par Anton Baltazarovič? La bibliothèque de son petit-fils comprenait bien - heureuse découverte! - un exemplaire des Kerčenskie drevnosti [Antiquités de Kertch] colorié ${ }^{85}$. Mais il ne portait ni annotation ni mention du nom de son propriétaire. Il ne s'agissait manifestement pas de l'exemplaire personnel de l'auteur et il était dénué d'ex-libris. Un autre ouvrage de la plume d'Anton Baltazarovič, Vosporskoe Carstvo [Le Royaume du Bosphore]

avait été acheté chez un bouquiniste comme en attestait, en bas du troisième de couverture, l'ex-libris d'un antiquaire bien connu (fig. 6) ${ }^{86}$. Vasilij Ivanovič Kločkov (1861-1915) était le propriétaire d'une librairie très cotée à Saint-Pétersbourg où l'on pouvait rencontrer tant des écrivains que des antiquaires. Il publiait régulièrement des catalogues à l'attention des bibliophiles et revendit les bibliothèques d'aristocrates, celle du prince Semjon Mikhajlovič Voroncov (1823-1882) par exemple, unique descendant masculin du prince Mikhail Semjonovič Voroncov et héritier d'une de ses bibliothèques. Cet exemplaire fut peut-être acheté

84. Il s'agit d'un album de gravures accompagnant les poèmes de I. F. Bogdanovič "Dušen'ka», inventorié sous le numéro d'inventaire RG-1999-2061.

85. L'ouvrage porte le numéro d'inventaire R 16083. Je dois à Tatjana Al'bertovna Lebedeva, conservatrice en chef, et à Natalia Vsevolodovna Smolina, bibliothécaire, d'avoir pu me familiariser avec "l'héritage Ašik» conservé avec soin au musée de Iaroslavl.

86. L'ouvrage porte le numéro d'inventaire R 28164; l'ex-libris est l'œuvre de l'illustrateur, graphiste et aquarelliste Sergej Solomko. 
à Kločkov par Vladimir Antonovič Ašik, comme semble l'indiquer une date (1904) inscrite au crayon de papier dans l'ouvrage.

Vladimir Antonovič Ašik (1843-1917) hérita en effet du goût de son père pour les livres d'art et les collections monétaires et en poursuivit l'œuvre. Mais il dut vraisemblablement constituer sa propre collection en partant de rien (ou si peu) : il est en effet fort probable que la bibliothèque personnelle d'Anton Baltazarovič ait été vendue à sa mort, de même que toutes ses archives scientifiques et personnelles. Son fils Vladimir accumula bien vite gravures, monnaies et médailles, fit l'acquisition de nombreux livres rares et d'ouvrages spécialisés, ce que lui permettaient ses revenus d'inspecteur des finances au service de l'Administration des chemins de fer. À sa mort, la collection passa aux mains de son fils Nikolaj, puis de son cadet Viktor Vladimirovič (1905-1985). Ce dernier augmenta la collection monétaire paternelle qu'il doubla et réorganisa la bibliothèque en l'adaptant à ses goûts et intérêts - outre des ouvrages traitant des beaux-arts russes du XIX ${ }^{\mathrm{e}}$ à la première moitié du $\mathrm{XX}^{\mathrm{e}}$ siècle, Viktor Vladimirovič acquit également de nombreuses éditions rares. Mais "la collection Ašik» est surtout connue pour ses nombreuses peintures et ouvres graphiques se rapportant au XVIII e et à la première moitié du XIX ${ }^{\mathrm{e}}$ siècle.

\subsection{Du chandelier à l'aquarelle}

a) La qualité du coloriage aquarellé

M. I. Rostovcev le notait avec raison: seul un nombre limité d'exemplaires de l'opuscule a bénéficié d'un coloriage des planches. Cet apprêt suppose une manutention attentive et patiente qui augmente sensiblement le prix et la valeur de l'ouvrage. C'est pourquoi Ašik n'en a fait produire qu'une série restreinte destinée sans doute à ses protecteurs ou à quelques savants et aristocrates dont il souhaitait obtenir la sollicitude.

Les deux exemplaires des Kerčenskie drevnosti [Antiquités de Kertch] dont nous avons pu commander la reproduction (le volume de SaintPétersbourg a été photographié, celui de Iaroslavl a été scanné) ont manifestement profité de bonnes conditions de conservation. Bien que la reproduction numérique des planches se soit déroulée sans échelle colorimétrique (un outil d'usage courant chez les professionnels de la couleur permettant de comparer teintes et valeurs tonales d'une reproduction et 
du document original), nous avons pu nous convaincre de la qualité de la manutention et de la stabilité des teintes employées sur des planches ayant été aquarellées à la main.

Reproduite en pleine page pour permettre la comparaison (fig. 7), la planche IV des exemplaires de Saint-Pétersbourg et de Iaroslavl présente la paroi de la première chambre funéraire accueillant la banquette. Au-dessus de celle-ci, très certainement, le défunt est peint allongé, revêtu d'une tunique pourpre et tenant une grappe de raisins à la main. La scène de bataille équestre, souvent commentée, prend place sur le front saillant de la banquette funéraire, tandis que les caissons, prenant place au-dessus d'une ligne de pampres, s'inscrivent dans la courbure de la voûte. Ce sont à ces derniers détails que l'œil perçoit quelques différences dans l'intensité des teintes: le rouge des fleurs et fruits inscrits dans les caissons a blêmi, dans l'exemplaire de Saint-Pétersbourg, de même le vert des pampres semble moins intense que dans l'édition conservée à Iaroslavl ${ }^{87}$. Mais à en juger dans leur globalité, les deux planches sont identiques et les teintes aquarellées profitent d'un rendu équivalent, confirmant a priori le sentiment de M. I. Rostovcev.

b) La palette et les «roues de couleurs»

Lorsqu'il pénètre à l'intérieur du tombeau, Anton Ašik s'émerveille des compositions peintes et de l'intensité des couleurs qui y ont été préservées. Il répertorie alors du blanc, du noir, du rouge, du jaune, du bleu, du vert et du gris sur les parois des deux chambres sépulcrales. Curieux de savoir si cette palette chromatique trouvait une correspondance exacte dans les planches aquarellées de l'ouvrage d'Ašik, nous en avons sélectionné trois que nous jugeons particulièrement emblématiques du discours s'articulant à l'intérieur de l'hypogée (fig. 8). Toutes trois reproduisent des parois peintes de la première chambre funéraire: celle, à l'entrée dans le caveau, figurant une scène fameuse de pompa funebris; une autre, immédiatement voisine, accueillant la banquette funéraire; enfin, face au défunt, une séquence narrative répartie sur trois tableaux et narrant l'enlèvement de Perséphone.

87. Pareils écarts, somme toute de moindre importance, pourraient également s'expliquer par le paramétrage de l'appareil photographique ou/et du scanner employé. 
Fig. 7 - Superposition de la Planche IV de A. B. Ašik, Kerčenskie drevnosti o pantikapejskoj katakombe, ukrašennoj freskami [Les Antiquités de Kertch. Sur une catacombe peinte de Panticapée], Odessa, Tipografija A. Brauna, 1845. En haut (1), édition coloriée de Saint-Pétersbourg; en bas (2), édition coloriée de Iaroslavl. Infographie de D. Glauser (C) UNIL/IASA. 
Fig. 8 - Sélection de trois planches coloriées de l'édition de Saint-Pétersbourg (Pl. III, IV et V) et « roues des couleurs» correspondantes. Infographie de D. Glauser (C) UNIL/ IASA. 
À notre demande, un graphiste a produit un échantillonnage des teintes employées à l'aquarellage en disposant des «roues de couleurs» en face de chacune des planches choisies ${ }^{88}$. Le résultat de cette opération ne doit pas être considéré trop étroitement: il permet avant tout de disposer d'un moyen visuel adapté pour évaluer l'amplitude chromatique mise en œuvre lors du coloriage et de vérifier son adéquation aux dires d'Ašik. Par surcroitt, les descriptions des planches contiennent des indications chromatiques qui supposent un mélange de pigments, telle la tunique orange d'une servante, sur la planche VI, le péplum rose d'une femme, sur la même planche, ou encore l'habit lilas d'un autre personnage féminin, sur la planche XI. La palette énoncée au début de l'ouvrage s'agrandit de champs chromatiques supplémentaires au fil de la description. C'est aussi ce que l'on constate à la lecture des «roues de couleurs»: si l'on fait abstraction du blanc énuméré par Ašik, la gamme chromatique des parois peintes excède sensiblement le nombre articulé initialement (les six «couleurs») pour s'établir à 9 pour la première planche, voire à 11 pour les deux autres planches.

Quel profit tirer de ces premières observations? Pour préliminaires et relatives qu'elles puissent paraître, ces informations offrent pourtant un potentiel "brut» qui demande à être affiné et confronté aux données éventuellement disponibles pour d'autres tombeaux bosporans d'époque romaine parvenus jusqu'à nous en bon état de conservation (nous pensons en particulier aux analyses pigmentaires réalisées dans le tombeau de 1891). Les relevés en couleur d'autres tombeaux ouverts à Kertch, conservés dans les archives, constituent également un champ d'investigation remarquable d'où tirer les palettes chromatiques susceptibles, par croisements avec les résultats d'analyses physico-chimiques, de nous renseigner sur les préférences d'une époque, l'usage et la provenance des pigments.

c) Les possibilités d'éclairage dans le tombeau et le problème de la perception des couleurs

Accédant au caveau funéraire par un puits, Anton Ašik et son dessinateur se trouvent sans doute dans la nécessité d'éclairer l'espace souterrain

88. On nommera plus proprement ces dernières «disques chromatiques». Nous remercions David Glauser, graphiste, de son précieux concours à cette publication. 
qu'ils explorent. Au risque de paraître énoncer une lapalissade, il est fort vraisemblable que les compositions peintes se soient dévoilées à la lumière de chandelles, limitant ainsi autant le confort d'un séjour prolongé dans l'hypogée que faussant peut-être la perception de certaines teintes. Le dessin des peintures de la seconde chambre funéraire trahit une difficulté relevant de cet ordre; on sait en effet que, dans un environnement nocturne, l'œil met du temps à s'adapter et que la perception des couleurs n'est pas exactement identique à celle d'un environnement diurne.

Ainsi, le rendu des registres inférieurs de cette chambre pose-t-il problème au pictorialiste: sur trois des quatre parois, des cercles et des carrés sur la pointe, coloriés tantôt en rouge tantôt en vert pin (tirant vers le bleu), mais qu'Ašik décrit dans des combinaisons de "vert et rose» et "vert et rouge", évoquent à n'en pas douter un opus sectile imitant des porphyres (lapis porphyrites) ${ }^{89}$. Ce constat n'est pas sans incidence sur le plan chronologique, puisque l'usage du porphyre acquiert un statut symbolique dès le règne de Trajan en devenant un matériau impérial par excellence ${ }^{90}$. Notre attention est toutefois attirée par l'absence d'écrin pour ces cercles et carrés normalement inscrits pour les uns dans des carrés, pour les autres dans des cercles. Ce motif décoratif est du reste régulièrement employé dans les tombeaux bosporans, tel le tombeau Feldstein, le tombeau de 1884, le tombeau de 1872 (dit de Stasov) et d'autres encore.

Mécompréhension du motif? Inattention du dessinateur? Ou mauvais état de l'enduit peint? Il est bien sûr fort probable que le registre inférieur des parois latérales, contre lesquelles on déposa peut-être des catafalques en bois, subit quelque corruption due au processus de décomposition des matières organiques immédiatement voisines. Mais l'hypothèse d'un éclairage insuffisant (ou insatisfaisant) de cette partie des parois peintes, considérées rapidement - Ašik et Stefanskij se concentrant avant tout sur les compositions narratives plutôt que sur les motifs décoratifs - ne peut être écartée. Le manque de luminosité associé à la rapidité d'exécution

89. Voir A. B. Ašik, Kerčenskie drevnosti o pantikapejskoj katakombe, ukrašennoj freskami, chap. VI, p. 24-26 pour la variante "vert et rouge».

90. Ce que montre M. Mulliez, Le luxe de l'imitation. Les trompe-l'ail de la fin de la République romaine, mémoire des artisans de la couleur, p. 101 sq. 
des dessins auront conduit à omettre des détails (pourtant significatifs) du décor peint.

La publication récente des dessins de K. R. Begičev et de F. I. Gross conservés dans les Archives scientifiques de l'Institut d'histoire de la culture matérielle, à Saint-Pétersbourg, offre de nombreuses vues pittoresques des fouilles archéologiques telles qu'elles étaient menées durant les années 1850 à $1880^{91}$. On y découvre à plusieurs reprises des dessins reproduisant, à l'intérieur de monuments funéraires, des travailleurs au service du muséum de Kertch ou son directeur, lui-même occupé à consigner ses observations dans un carnet. Autant de tableaux qui les montrent invariablement une chandelle à la main, présence ténue au sein d'une obscurité oppressante, comme le décrira Ašik avec une certaine emphase ${ }^{92}$. À titre d'exemple, citons les planches 86 et 87 de l'ouvrage de Ju. A. Vinogradov qui accompagnaient le rapport de Aleksandr Efimovič Ljucenko, directeur du muséum de Kertch, envoyé à la Commission archéologique impériale, à Saint-Pétersbourg. Le dessinateur F. I. Gross y figure son collègue Ljucenko, visitant une hypogée chrétienne creusée dans le flanc septentrional du mont Mithridate, à Kertch. Le chandelier est l'allié inaltérable de l'archéologue qui s'en sert, en 1862, comme unique source de luminosité 93 .

\section{Conclusions}

La documentation d'archives, nous l'avons vu, constitue un gisement incomparable d'informations pour restituer des monuments de l'Antiquité gréco-romaine aujourd'hui disparus. Le cas du tombeau de 1842 ouvert par Anton Ašik en est une illustration pour Kertch et l'archéologie bosporane: au prix d'une attention méticuleuse et d'une base documentaire solidement étayée permettant le croisement de données,

9I. Voir Ju. A. Vinogradov, Drevnosti Bospora Kimmerijskogo v risunkakh K. R. Begičev i F. I. Gross.

92. Voir A. B. Ašik, Kerčenskie drevnosti o pantikapejskoj katakombe, ukrašennoj freskami, chap. I, p. 3.

93. D'autres planches du même ouvrage montrent des scènes identiques: un moujik dans la chambre funéraire du kourgane Melek-Česmé (tabl. 3, p. 40 - dessin de Begičev) ou encore la découverte des peintures du kourgane de Bol’šaja Bliznica (tabl. 47 et 48, p. 84 sq. - dessins de Gross). 
les découvertes du XIX ${ }^{e}$ siècle, que l'on croit souvent scientifiquement inexploitables, livrent de nouvelles informations et affinent notre perception de cette époque qui vécut les balbutiements de l'archéologie. D’antiquaire amoureux des «curiosités» que produisait l'Antiquité grécoromaine, de pourvoyeur de "trésors" que l'Ermitage impérial réclamait, Anton Ašik allait faire quelques pas en direction de l'archéologue qui cherche à systématiser une approche, à valider une méthode, à documenter son terrain et à consulter ses collègues pour mieux appréhender le fruit de ses investigations.

L'exploration des collections muséales, à Saint-Pétersbourg et à Iaroslavl, a été couronnée de succès: les éditions coloriées de l'ouvrage d'Ašik apportent de nouveaux éléments au dossier des compositions peintes et incitent à reprendre le fil d'une recherche close par M. I. Rostovcev en 1914. Des investigations nouvelles doivent encore concerner la critique de son ouvrage par ses contemporains, en particulier l'accueil qui lui fut réservé à Saint-Pétersbourg, et déboucher sur une analyse des compositions peintes à peine entamée dans cette contribution. Il ne fait pas de doute que le tombeau de 1842 a encore beaucoup de choses à nous apprendre...

Pascal Burgunder

Pôle de recherche «Études Bosporanes» Institut d'archéologie et des sciences de l'antiquité Université de Lausanne 


\section{BIBLIOGRAPHIE}

AšıK, Anton Baltazarovič, "Kerčenskie katakomby» [«Les catacombes de Kertch»], Žurnal Ministerstva Vnutrennikh Del, 10 (1845), p. $400-408$.

-, Kerčenskie drevnosti o pantikapejskoj katakombe, ukrašennoj freskami [Les Antiquités de Kertch. Sur une catacombe peinte de Panticapée], Odessa, Tipografija A. Brauna, 1845.

-, Vosporskoe Carstvo s ego paleografičeskimi i nadgrobnymi pamjatnikami, raspisnymi vazami, planami, kartami i vidami [Le Royaume du Bosphore avec ses monuments paléographiques et funéraires, ses vases peints, des plans, des cartes et des vues], Odessa, Tipografija T. Nejmana i komp., 1848 (partie 1 et 2), 1849 (partie 3).

Bernštam, Aleksandr Natanovič, Bibikov, Sergej Nikolaevič, «N. I. Repnikov (1882-1940). Nekrolog» [N. I. Repnikov. Une nécrologie], in Kratkie Soobščenija Instituta Istorii Material'noj Kul'tury 9, Moskva/Leningrad, Akademija Nauk SSSR, 1941, p. 121-123.

Burgunder, Pascal, "Des lumières de la tombe d'Ašik», in Lychnological Acts I, éd. par Laurent Chrzanovski, Genève/Nyon, Monique Mergoil, 2003, p. 45-50.

Burlot, Delphine, Peintures romaines antiques et faussaires. Sources et techniques, thèse, Université Paris-Sorbonne - Paris IV, 2007 (consultable en ligne: <https://tel.archives-ouvertes.fr/tel00778669>).

Butjagin, Aleksandr Mikhailovič, Vinogradov, Jurij Alekseevič, JuzOba. Kurgannyj nekropol' aristokratii Bospora. T. II. Kurgany na myse Ak-Burun [Juz-Oba. Une nécropole tumulaire de l'aristocratie du Bosphore. T. II. Les kourganes du cap Ak-Burun], Simferopol'/ Kertch, Fondation "Demetra» et Institut oriental de l'Académie nationale des sciences d'Ukraine, 2014.

Creuzer, Friedrich, Symbolik und Mythologie der alten Völker, besonders der Griechen, Leipzig/Darmstadt, C. W. Leske, 1810-1812. 
Dlužnevskaja, Galina Vaclavovna, Medvedeva, Marija Vladimirovna, Platonova, Nadežda Igorevna, Musin, Aleksandr Evgen'evič, "Slavjano-russkie i srednevekovye drevnosti v issledovanijakh imperatorskoj arkheologičeskoj komissi» [ "Les antiquités slavorusses et médiévales dans les investigations de la Commission archéologique impériale»], in Imperatorskaja arkheologičeskaja komissija (1859-1917) [La Commission archéologique impériale (1859-1917)], otv. red. Aleksandr Evgen'evič Musin, Evgenij Nikolaevič Nosov, Sankt-Peterburg, Dmitrij Bulanin, 2009, p. 813-908.

Gajdukevič, Viktor Francevič, «Bosporskie pogrebal'nye sklepy V-IV vv. do n.è. s ustupčatym pokrytiem" ["Les caveaux funéraires bosporans des $\mathrm{V}^{\mathrm{e}}$ et $\mathrm{IV}^{\mathrm{e}}$ siècle av. notre ère avec voûte en encorbellement»], in V. F. Gajdukevič: Bosporskie goroda [V. F. Gajdukevič: les cites du Bosphore], otv. red. Anatolij Leopol'dovič Jakobson, Leningrad, Nauka, 1981, p. 6-54.

Gille, Florian, Antiquités du Bosphore Cimmérien conservées au Musée impérial de l'Ermitage. Ouvrage publié par ordre de sa Majesté l'Empereur, Saint-Pétersbourg, imprimerie de l'Académie Impériale des Sciences, 1854.

Gorončarovskij, Vladimir Anatol'evič, Meždu imperiej $i$ Varvarami: voennoe delo Bospora Rimskogo vremeni [Entre l'Empire et les Barbares: les militaria du Bosphore à l'époque romaine], SanktPeterburg/Moskva, Peterburgskoe Vostokovedenie, 2003.

Grač, Nonna Leonidovna, Nekropol' Nimfeja [La nécrople de Nymphaion], Sankt-Peterburg, Nauka, 1999.

Guimier-Sorbets, Anne-Marie, Pelle, André, Seif el-Din, Mervat, Renaître avec Osiris et Perséphone, Alexandrie, Centre d'Études Alexandrines, 2015.

Heurgon, Jacques, "La découverte des Étrusques au début du $\mathrm{XIX}^{\mathrm{e}}$ siècle", Comptes rendus des séances de l'Académie des Inscriptions et Belles-Lettres, 117/4 (1973), p. 591-600.

Jurova, Ljubov' Leonidovna (otv. red.), Semejnoe prizvanie. Kollekcii Ašikov [Une vocation familiale. Les collections des Ašik], Jaroslavl', Jaroslavskij khudožestvennyj muzej, 2006.

—, "Introduction", in Semejnoe prizvanie. Kollekcii Ašikov [Une vocation familiale. Les collections des Ašik], otv. red. Ljubov' Leonidovna 
Jurova, Jaroslavl', Jaroslavskij khudožestvennyj muzej, 2006, p. 5-13.

KJone, Boris Vasil'evič, «Recenzija sočinenija G. Ašika: Kerčenskija drevnosti. O Pantikapejskoj katakombe, ukrašennoj freskami, Odessa, 1845» ["Recension de l'ouvrage de Monsieur Ašik: Les Antiquités de Kertch. Sur une catacombe peinte de Panticapée»], Finskij vestnik za ijun' 1847 g., 1847, p. 26-31.

—, "Otčjot o sočinenii G. Ašika, pod zaglaviem: Kerčenskija drevnosti. O Pantikapejskoj katakombe, ukrašennoj freskami. Odessa, 1845" [«Rapport portant sur le mémoire de Monsieur Ašik intitulé: Les Antiquités de Kertch. Sur une catacombe peinte de Panticapée»], Zapiski Sankt-Peterburgskogo arkheologo-numizmatičeskogo obščstva, I (1849), p. 89-96.

Köhne, Bernhard de, "A. Ašik, Antiquités de Kertsch: catacombe de Panticapée avec des fresques peintes", Mémoires de la Société d'archéologie et de numismatique de Saint-Pétersbourg, I (1847), p. 201-207.

Konovalova, Natalja Olegovna, "Ašiki - dinastija kollekcionerov", Naše nasledie, 61 (2002), p. 129-135.

KorČEnov, Viktor Konstantinovič, "Slavnaja dinastija dvorjan Ašikov i Odessa» "La glorieuse dynastie des nobles Ašik et Odessa»], à consulter en ligne: <https://www.odessitclub.org/index.php/ chitalnyi-zal/2059-slavnaya-dinastiya-dvoryan-ashikov-i-odessa>.

Kulakovskij, Julian, Dve Kerčenskie katakomby s freskami [Deux catacombes de Kertch avec fresques], Sankt-Peterburg, Imperatorskaja Arkheologičeskaja Komissija, 1896, (Materialy po Arkheologii Rossii, 19).

Lazenkova, Lidija Mikhajlovna, Kerčenskij muzej drevnostej. Osnovateli - issledovateli [Le Musée des antiquités de Kertch. Fondateurs et chercheurs], Kertch, Kerčenskij Gosudarstvennyj istoriko-kul'turnyj zapovednik, 2003.

Lebedynsky, Iaroslav, Les Sarmates, Paris, Errance, 2002.

Maslennikov, Aleksandr Aleksandrovič, Semejnye sklepy sel'skogo naselenija pozdneantičnogo Bospora [Tombeaux familiaux de la population rurale du Bosphore tardo-antique], Moskva, Institut arkheologii RAN, 1997. 
Matveev, A. A., K voprosu ob arkheologičeskikh issledovanijakh v Južnoj Rossii [À propos des investigations archéologiques menées en Russie méridionale], vol. III, Odessa, 1884.

Mielczaren, Mariusz, Cataphracti and clibanarii. Studies on the haevy armoured cavalry of the ancient world, Łódź, Oficyna Naukowa MS, 1993.

-, The army of the Bosporan kingdom, Łódź, Oficyna Naukowa MS, 1999.

Mulliez, Maud, Le luxe de l'imitation. Les trompe-l'ail de la fin de la République romaine, mémoire des artisans de la couleur, Naples, Centre Jean Bérard, 2014.

Nefjodkin, Aleksandr Konstantinovič, Pod znamenem drakona. Voennoe delo Sarmatov vo II v. do n.è. - V v. n.è. [Sous le signe du dragon. Les militaria des Sramates du II siècle av. notre ère au $V^{e}$ siècle de notre ère], Sankt-Peterburg/Moskva, Peterburgskoe Vostokovedenie, 2004.

Ravdonikas, Vladislav Iosifovič, "Pamjati N. I. Repnikova» ["En mémoire de N. I. Repnikov»], in Staraja Ladoga [Staraja Ladoga], otv. red. Vladislav Iosifovič Ravdonikas, Leningrad, Gosudarstvennyj Muzej Ètnografii, 1948, p. 6-10.

Rochette, Raoul, Tableau des catacombes de Rome, Paris, Bibliothèque universelle de la jeunesse, 1837.

Rostovcev, Mikhail Ivanovič, Antičnaja dekorativnaja živopis' na juge Rossii [La peinture décorative antique en Russie méridionale], SanktPeterburg, Izdanije Imperatorskoj Archeologičeskoj Kommissii, 1913-1914.

Rostovtseff, Mikhaïl, La peinture décorative antique en Russie méridionale (Saint-Pétersbourg, 1913-1914), dir. Alix Barbet, trad. Arlette Fraysse et Andrea Rychtecky, 2 vols, Paris, de Boccard, 2004 (Mémoires de l'Académie des inscriptions et belles-lettres, XXVIII).

Tunkina, Irina Vladimirovna, Russkaja nauka o klassičeskikh drevnostjakh juga Rossii (XVIII - seredina XIX vv.) [La recherche scientifique russe sur les antiquités classiques de la Russie méridionale (XVIII ${ }^{e}$ première moitié du XIX ${ }^{e}$ siècle)], Sankt-Peterburg, Nauka, 2002.

Vinogradov, Jurij Alekseevič, "Kurgan Kul'-Oba» ["Kourgane de Koul-Oba»], in Pol'Djubrjuks. Sobranie sočinenij [Paul Dubrux. 
Euvres complètes], I, otv. red. Irina Vladimirovna Tunkina, Sankt-Peterburg, Kolo, 2010, p. 420-425.

—, «Zolotoj kurgan (Altyn-Oba)» [«Le kourgane d'Or (Altyn-Oba)»], in Pol'Djubrjuks. Sobranie sočinenij [Paul Dubrux. Euvres complètes], I, otv. red. Irina Vladimirovna Tunkina, Sankt-Peterburg, Kolo, 2010, p. 471-476.

-, Drevnosti Bospora Kimmerijskogo v risunkakh K. R. Begičev i F. I. Gross [Les antiquités du Bosphore Cimmérien dans les dessins de K. R. Begičev et de F. I. Gross], Simferopol'/Kertch, Fondation «Demetra», 2017.

Vinogradov, Jurij Alekseevič, Gorončarovskij, Vladimir Anatol'evič, Voennaja istorija i voennoe delo Bospora Kimmerijskogo (VI v. do n.è. - seredina III v. n.è.) [Histoire militaire et militaria du Bosphore Cimmérien (du VIe siècle avant notre ère au milieu du III siècle de notre ère)], Sankt-Peterburg, Nestor-Istorija, 2009.

Vinogradov, Jurij Alekseevič, Medvedeva, Marija Vladimirovna, «Iz istorii sozdanija "Antičnoj dekorativnoj živopisi na juge Rossii" M. I. Rostovceva» ["Historique de la rédaction de "La peinture décorative antique en Russie méridionale” de M. I. Rostovcev»], in Antičnaja dekorativnaja živopis' Bospora Kimmerijskogo: ot grafičeskoj fiksacii $k$ fotografii [La peintre décorative antique du Bosphore Cimmérien: de la fixation graphique à la photographie], otv. red. Jurij Alekseevič Vinogradov, Marija Vladimirovna Medvedva, Sankt-Peterburg, Lema, 2017, p. 9-30.

Vinogradov, Jurij Alekseevič, Zin'ko, Viktor Nikolaevič, Smekalova, Tat' jana Nikolaevna, Juz-Oba. Kurgannyj nekropol' aristokratii Bospora, T. I. Istorija izučenija i topografija [Juz-Oba. Une nécropole tumulaire de l'aristocratie du Bosphore. T. I. Histoire de l'exploration et topographie], Simferopol'/Kertch, Fondation "Demetra» et Institut oriental de l'Académie nationale des sciences d'Ukraine, 2012. 



\section{ANNEXE DES PLANCHES}

Anton Baltazarovič Ašın, Kerčenskie drevnosti o pantikapejskoj katakombe, ukrašennoj freskami [Les Antiquités de Kertch. Sur une catacombe peinte de Panticapée], Odessa, Tipografija A. Brauna, 1845.

Édition coloriée du Musée russe d'Ethnographie, Saint-Pétersbourg (No inv. I.D. 226).

Photographies de Ol'ga Vladimirovna Ganičeva. 